\title{
An Autonomous Reactivity Control System for Improved Fast Reactor Safety
}

\author{
Staffan Qvist ${ }^{\mathrm{a}, b^{*}}$ and Ehud Greenspan ${ }^{\mathrm{b}}$ \\ ${ }^{a}$ Department of Physics and Astronomy, Uppsala University, Sweden \\ ${ }^{b}$ Nuclear Engineering Department, University of California Berkeley, USA
}

*Corresponding author

Email-address: staffanq@gmail.com

Mailing address: Döbelnsgatan 89, 11352, Stockholm, Sweden

Phone-number: +46765624043 


\begin{abstract}
The Autonomous Reactivity Control (ARC) system is a new safety device that can passively provide negative reactivity feedback in fast reactors that is sufficient to compensate for the positive coolant density reactivity feedback even in large low-leakage cores. The ARC system is actuated by the inherent physical property of thermal expansion, and has a very small effect on core neutronics at standard operating conditions. Additionally, the ARC system does not have an identified failure mode that can introduce positive reactivity in to the core. An ARC system can be installed in conventional fuel assemblies by replacing a limited number of fuel rods with rods that fill a safety function, providing negative reactivity to the core in the event of coolant temperature rise above nominal. These rods are of the same outer dimensions as the fuel rods, but contain smaller-diameter inner rods that are connected to liquid-filled reservoirs at the top and bottom of the assemblies. The reservoirs are filled with two separate liquids that stay liquid and immiscible throughout the applicable temperature range of fast reactor operation. The lower reservoir contains a "neutron poison" liquid with a high neutron absorption cross-section. The upper reservoir is filled with a separate liquid with a small neutron absorption cross-section. As the temperature in the assembly increases, the liquids in the reservoirs thermally expand, effectively pushing the absorbing liquid up toward the active core region while compressing the inert gas that fills the volume above the liquid between the inner and outer tubes of the ARC rods. The ARC system can be installed, or retrofitted in to existing systems, in every fuel assembly in the core. Since ARC installations in individual fuel assemblies operate independently, the system has a high level of redundancy. ARC-systems respond to local transients as well as core-wide accident scenarios. After actuation, the system automatically returns to its initial state as temperatures decrease, without the need for intervention by reactor operators. The ARC system concept and design considerations are described and illustrated.
\end{abstract}

Keywords: Fast reactors, Safety, Autonomous reactivity feedback, Fuel assembly 


\section{Introduction}

Much of the current focus of safety design for new nuclear reactors is on inherent safety features. Inherent safety means that the reactor design is such that the plant remains in a safe condition solely on the basis of the laws of nature; these laws ensure that all performance characteristics remain within safe bounds under all conceivable circumstances. This implies that no human intervention, no triggering signals and no supply of external energy are required for the reactor to remain in a safe condition [1]. Inherent safety features are especially important when engineered systems such as the SCRAM-systems for reactor shutdown are not functioning.

Thermal reactor cores are designed to be slightly under-moderated to ensure that a decrease of the coolant density reduces the reactivity of the system. Thus, in a properly designed Light Water Reactor (LWR) there are no positive temperature reactivity feedbacks. In contrast, in most fast reactor cores coolant density reduction - due to increased temperature or voiding, has a positive reactivity feedback. This is because the core-averaged number of fission neutrons produced per absorption $(\eta)$ increases because of neutron spectrum hardening. Coolant density decrease also causes an enhancement of the neutron leakage probability, which, in turn, introduces negative reactivity feedback. In most fast reactors the positive reactivity added by spectrum hardening (and, to a smaller extent, by reduced neutron capture probability in the coolant) due to a coolant density decrease in the central region of the core is larger than the negative reactivity introduced by the enhanced neutron leakage. The extreme case of such an event is coolant voiding due to boiling or loss of coolant accidents. Reducing the positive feedback associated with coolant density reduction and increasing the magnitude of negative feedback of other mechanisms while maintaining acceptable core performance has been a major focus of fast reactor safety research. The main mechanisms that inherently provide negative reactivity feedback in fast reactor cores are defined in Figure 1. The red arrows indicate the directions of motion of the component that causes the negative feedback. 


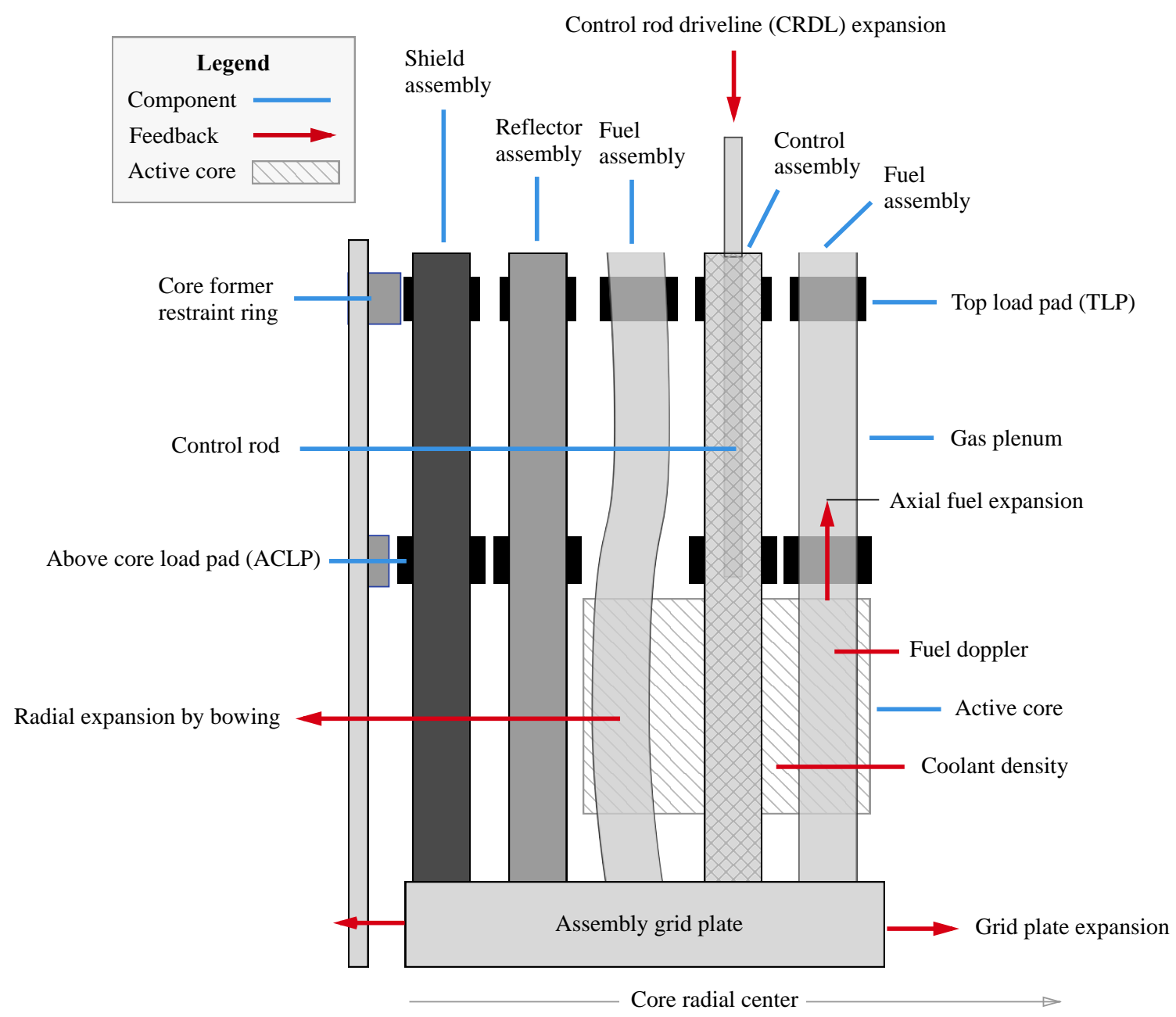

Figure 1, Dimensional changes and corresponding reactivity feedback mechanisms in a conventional fast reactor core

Figure 2 shows the possible event-initiating perturbations (blue boxes), the resulting component temperature changes (black squares), the main ${ }^{1}$ resulting reactivity effects and the associated reactivity feedback definitions for a conventional fast reactor core. 


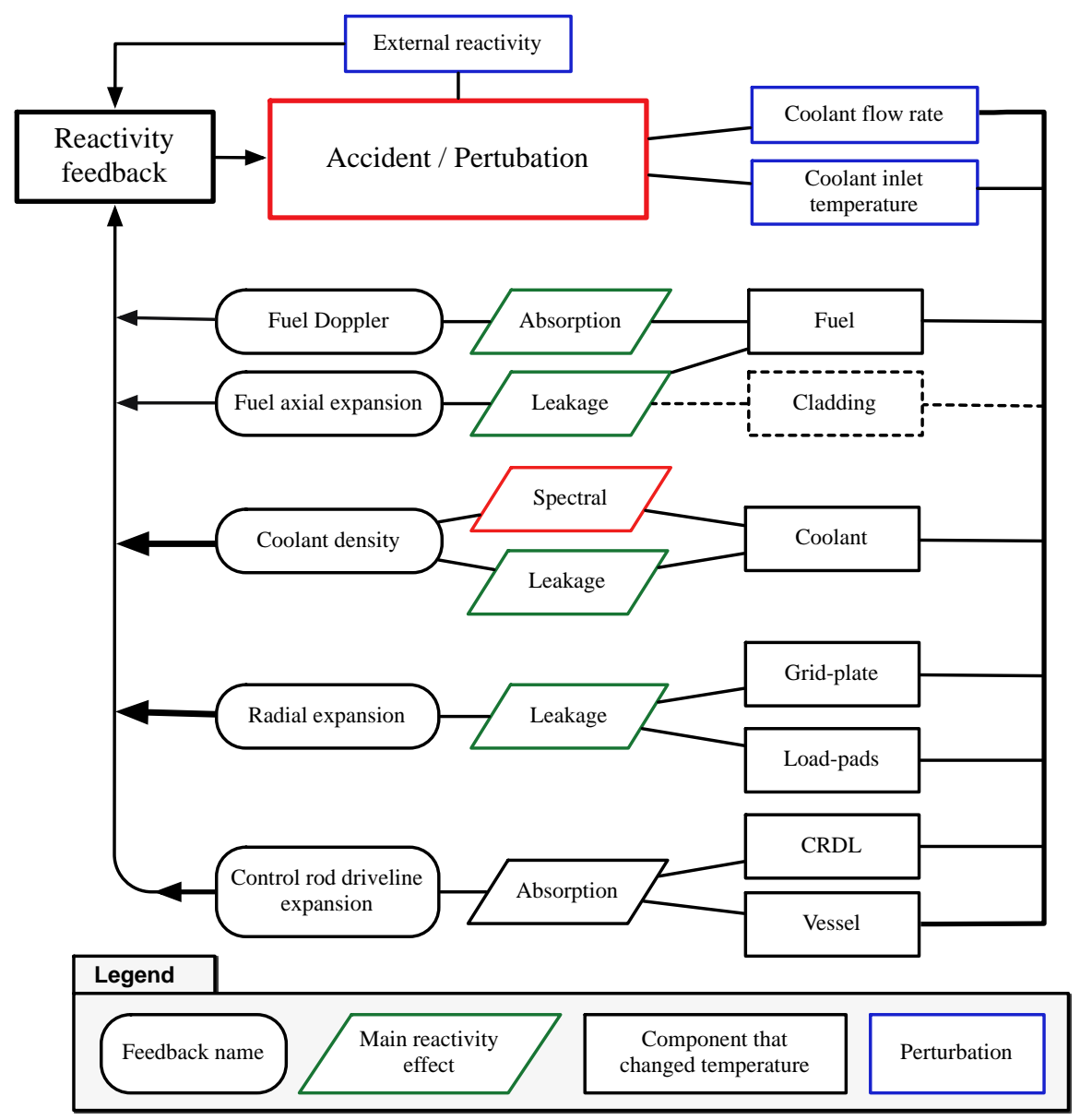

Figure 2, Fast core reactivity initiating events and feedback mechanism at play

The effects shown in Figure 2 represent the largest and most important reactivity feedback effects; they do not represent all effects occurring in the core. A green-box indicates a negative temperature reactivity feedback and a red box a positive feedback. The black reactivity box shows an effect where the sign of the feedback is time-dependent as in case of control rod driveline expansion. Initially as the control rod driveline (CRDL) heats up, control rods are inserted into the active core causing a negative reactivity feedback. At a later stage, the reactor vessel heats up and expands, effectively pulling the control rods back out of the core, resulting in a positive feedback.

A combination of the inherent feedbacks shown in Figure 2 should keep peak temperatures below safety margins in unprotected transients such as loss of flow (ULOF), loss of heat sink (ULOHS) and the inadvertent ejection of control rod(s) resulting in a transient overpower event (UTOP). However, it is very difficult to design a low-leakage reactor core, such as required for breed-and-burn reactors [2], to have a combination of inherent reactivity feedbacks to keep core component temperatures sufficiently low in accidents. If the nominal neutron leakage probability is small - a requirement for a good neutron economy, the negative feedbacks connected to changes in the relative leakage probability will have a small impact on 
the core reactivity. A low-leakage core does not only have smaller magnitude negative feedback, but larger magnitude positive feedbacks. This is because the negative component of the feedback, which is leakagebased, is reduced, while the positive spectral component remains essentially unchanged. This makes it extremely challenging, if not impossible, to design large low-leakage fast reactor cores to be inherently safe without use of passively actuated engineered reactivity control systems

To objective of this work is to describe the Autonomous Reactivity Control (ARC) system that was invented to overcome the issue of too positive coolant temperature feedback and too large positive coolant void worth without significantly impairing the core neutron economy in standard operating conditions.

Section 2 defined a set of evaluation criteria for systems and solutions aimed at improving the reactivity feedback of fast reactor cores. Using these criteria, Section 3, 4, 5 and 6 evaluates already proposed solutions based on leakage, moderation, solid absorbers and liquid absorbers respectively. The evaluation of existing solutions is summarized in Section 7. The Autonomous Reactivity Control (ARC) system is introduced in Section 8. Section 9 presents different approaches for designing the reactivity response of ARC-type systems. In Section 10, possible combinations of materials for ARC-systems are presented. The system design methodology, based on the approaches defined in Section 9, is briefly introduced in Section 11. Section 12 presents the characteristics and performance of an ARC-system installation in a large fast reactor core. Finally, Section 13 summarizes conclusions and directions for further study in the future.

\section{Reactivity-safety evaluation criteria for fast reactors}

To systematically evaluate different approaches for improving reactor safety, a set of 23 different evaluation criteria are defined and summarized in Table 1. Initially, an attempt was made to assign relative weighing factors to each criterion of Table 1 in order to be able to better quantify differences between approaches. As analysis progressed it was realized that it is more efficient to treat the criteria in a quasibinary fashion: solutions are assigned a pass, fail or conditional fail on all the criteria of Table 1. A conditional fail indicates a potential problem that may be alleviated by careful design and analysis, and is thus not a showstopper. Assigning numerical values to the different categories of evaluation criteria (which is the norm) does not work, as a solution could score a high overall value (and thus be ranked high) but have a single drawback that still precludes its use. Self Actuated Shutdown Systems (SASS) fulfill an inherent/passive safety function but have been omitted from this evaluation. While other systems and design-approaches impact the physical behavior of the core itself, SASS-systems are essentially SCRAM systems that are actuated passively. SCRAM operations of any type in a fast reactor are events that should, if possible, be avoided. The resulting thermal shocks may damage and/or reduce the lifetime of corecomponents. Thus, the applicability of most SASS solutions is more as backup for conventional SCRAM systems rather than an added inherent safety design feature. 
Table 1, System evaluation criteria for neutronically efficient fast reactors

\section{Designation Description}

\begin{tabular}{ll}
\hline A. & System operation efficiency \\
\hline A1. & Significantly improves system response to transients \\
A2. & Has no credible failure mode that introduces positive reactivity \\
A3. & Operates passively/inherently \\
A4. & Has no moving mechanical parts \\
A5. & Operates continuously \\
A6. & Is not significantly degraded by time and/or burnup/fluence \\
A7. & General accident scenario applicability \\
A8. & Seismically stable \\
\hline B. & Impact on neutron economy at standard operation \\
\hline B1. & Spectral degradation \\
B2. & Leakage impact \\
B3. & Absorption impact \\
\hline C. & Impact on core operation \\
\hline C1. & Interferes with fuel shuffling operations \\
C2. & Complicates start-up and shutdown \\
\hline D. & Impact on core and reactor cost \\
\hline D1. & Core size and reactor vessel dimensions \\
D2. & Solution component costs \\
D3. & Core performance degradation costs \\
\hline E. & System complexity and predictability \\
\hline E1. & Non-nuclear testability \\
E2. & Modeling complexity \\
E3. & Operational uncertainties \\
E4. & Redundancy \\
\hline & Licenseability in current licensing frameworks \\
\hline &
\end{tabular}

\section{Leakage based solutions}

\subsection{Introduction}

The main focus of reactivity feedback improvement and void worth reduction work worldwide has been on leakage-based methods. This is because the main negative component of the reactivity effect of coolant voiding is the increase in neutron leakage from the core (as stated in Section 1, changes in coolant absorption rates can effectively be ignored). When the relative importance of neutron leakage in the core is increased, the leakage component of the void reactivity will increase and eventually dominate the positive 
spectral component, resulting in a negative total void worth. Ideally, a leakage-based void-worth-reducing design should feature low leakage during standard operation, while strongly increasing leakage in the voided state. However, such ideal (for the neutron economy) designs have not been identified. Leakagebased systems and designs for safety are in direct opposition to the operational requirements of neutronically efficient cores such as breeders and Breed \& Burn systems.

\subsection{Reducing the core height-to-diameter (H/D) ratio}

A common approach to improve fast core reactivity safety has been to design cores to have a large axial neutron leakage probability by restricting the height of the active core region to the vicinity of $100 \mathrm{~cm}$. By sufficiently reducing the core height it is even possible to achieve negative void worth as, for example, in versions of the Integral Fast Reactor (IFR) [3]. The restriction on the effective core height has led large core designs to be extremely "pan-cake" shaped. For example, the Russian BN-1200 core design has an active core diameter of 5.2 meters with an active core height of $84 \mathrm{~cm}$, giving an H/D ratio of $\sim 0.16$ [4]. The height and diameter of the active core (radial blanket regions excluded) in 34 major fast reactor concepts are displayed in Figure 3.

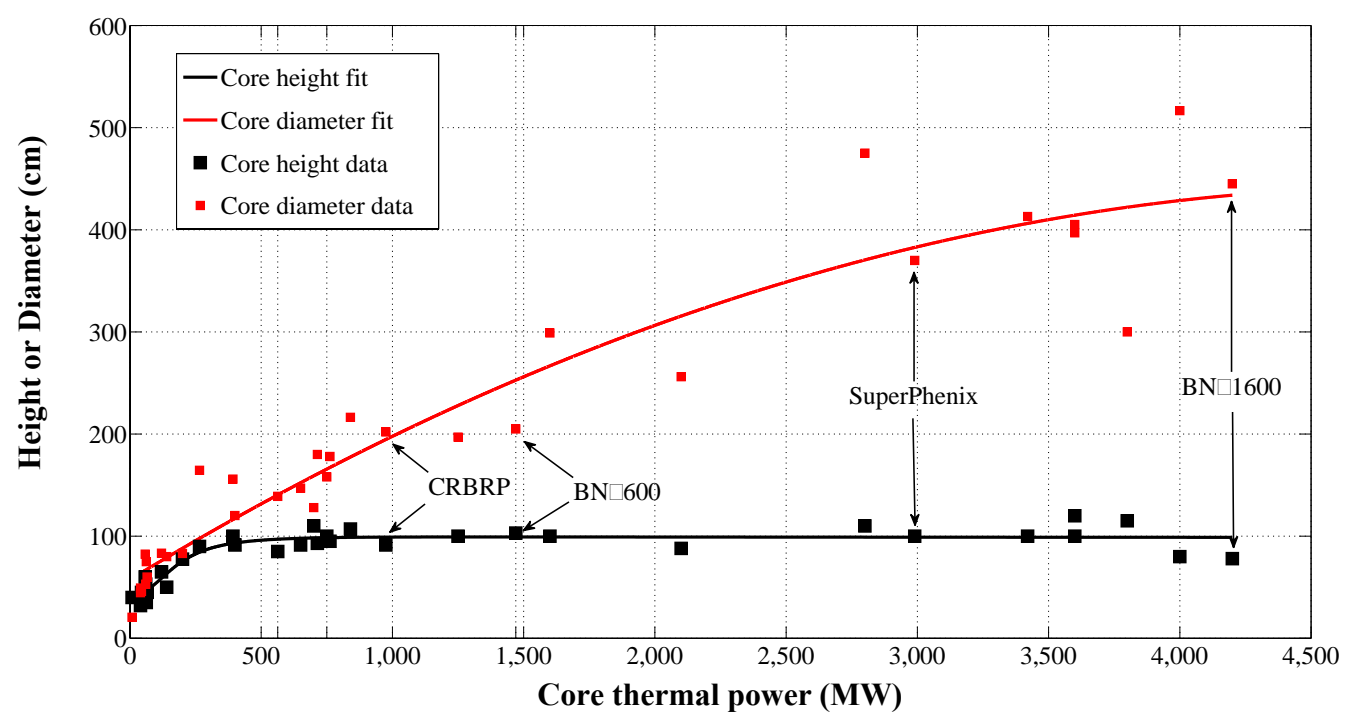

Figure 3, Active core height and diameter of 34 major fast reactor core concepts. Developed from data in ref. [5].

While there are other advantages to a short fuel height, including a smaller friction pressure drop across the fuel assemblies and higher assembly power density, the main reason for the trend of reduced H/D with core size is reactor safety. However, the enhanced leakage probability of the small H/D cores significantly penalizes the core neutron economy and, hence, core breeding ability. The optimal shape of a given volume cylindrical uniform composition core predicted by one-group diffusion theory (described by Error! Reference source not found. and Error! Reference source not found.) to give the minimum neutron leakage probability is a height-to-diameter ratio of $\mathrm{H} / \mathrm{D}_{\text {optimal }}=0.924$. 


$$
k_{e f f}=\frac{k_{\infty}}{1+B^{2} M^{2}}
$$

where $\mathrm{M}^{2}$ is the migration area and $\mathrm{B}^{2}$ the geometric buckling, given by:

$$
B^{2}=\left(\frac{\pi}{H}\right)^{2}+\left(\frac{2.4048}{R}\right)^{2}
$$

Figure 4 illustrates the sensitivity of the effective core multiplication factor on core shape as predicted by the one-group diffusion theory for uniform homogeneous cores. The migration length $(M)$ was set to 19.2 $\mathrm{cm}$, typical for a sodium-cooled reactor [6] and $\mathrm{k}_{\text {inf }}$ was set to 1.2. The reflector effect is neglected for this highly simplified analysis. The total core volume is kept constant (at $35.4 \mathrm{~m}^{3}$, which yields $\mathrm{k}_{\text {eff }}=1.0$ at $\mathrm{H} / \mathrm{D}=0.924)$ while the shape is varied.

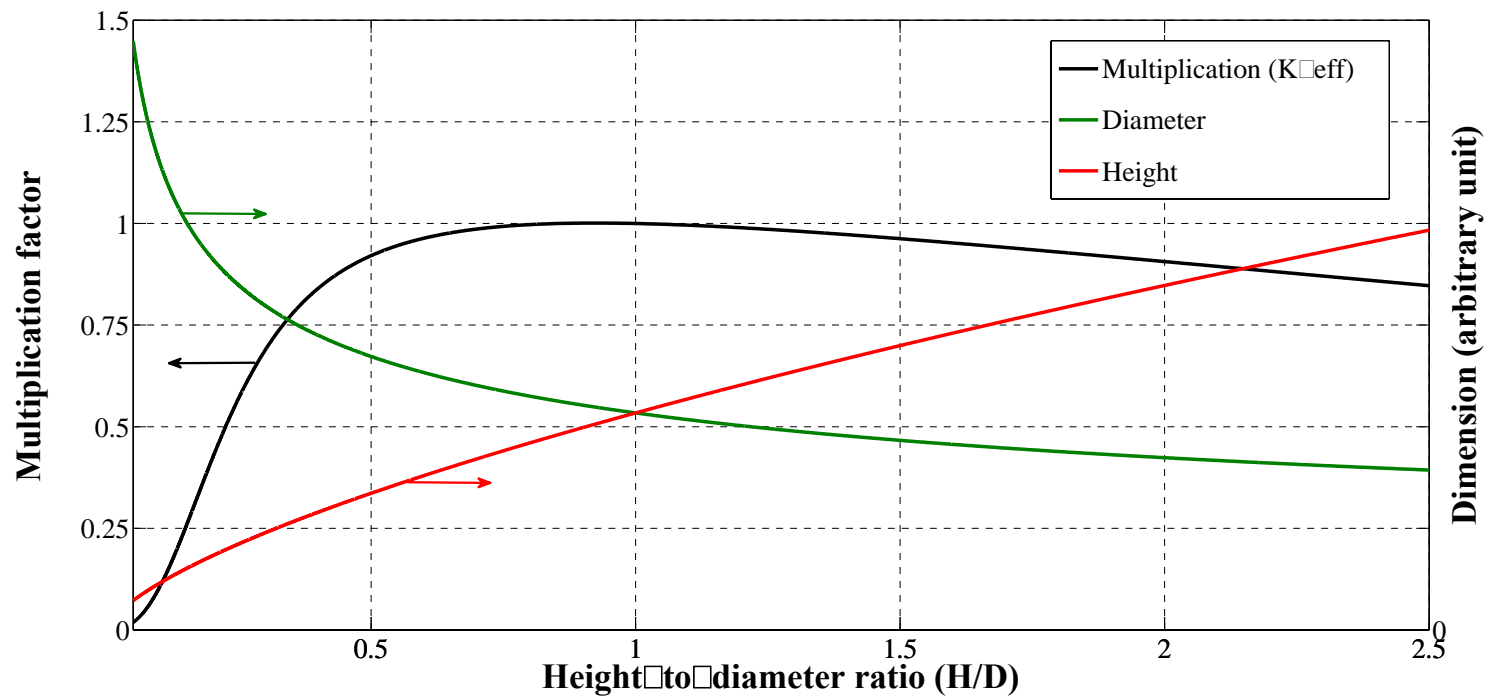

Figure 4, Core shape impact on $\mathrm{k}_{\text {eff }}$ in cylindrical homogeneous reactors in one-group diffusion theory

The drop in $\mathrm{k}_{\text {eff }}$ by a non-optimal shape must be compensated either by increasing the density of fissile material in the core, or increasing the overall active core volume. Such design changes penalize the fast reactor economics. In summary, reducing the active core height enables a reduction of the magnitude of the positive coolant temperature and voiding reactivity feedback, achieving a negative power reactivity feedback but results in a detrimental effect on the neutron economy. The solution fails criteria B2, D1 and D2 of Table 1. 


\subsection{Gas expansion modules (GEM)}

One of the first systems specifically designed to reduce reactivity through leakage in accident scenarios is the GEM system developed at FFTF in the 1980s [7]. GEMs are empty assemblies located between the outer fuel assembly row and the reflectors. They are sealed at the top but open at the bottom and filled in their upper part with a pressurized gas. During standard operation, coolant flow provides upward pressure inside the GEM that compresses the gas so that it stays above the active core region. When flow decreases in a loss of flow (LOF) accident, the gas expands into the core region and thereby reduces the neutron reflection and hence, the core reactivity. While GEMs are conceptually both simple and brilliant and worked well in the FFTF, they are effective only if the neutron importance in the outer core region is sufficiently high. This is not the case in large diameter cores having low radial leakage probability. In addition, GEMs only respond to one accident scenario (LOF), and concerns have been raised about the potential response of the core to gas leakage from the GEMs. If a GEM system fails and gas is leaked, it has the potential for a positive reactivity insertion. The GEM-system is a brilliant passive safety system that improves core reactivity feedback without degrading core performance. The system directly fails criteria A2, A7 and C2 of Table 1. It is only effective enough to abide by the rest of the Category A criteria if criterion B2 is violated by the baseline core design, which makes it conditionally fail criteria B2.

\subsection{Strongly heterogeneous core design}

It has been shown that carefully designed strongly heterogeneous cores with different fuel heights and introduction of internal blankets in different parts of the core as well as absorbers in the vicinity of the core can reduce the void worth and improve feedback without significantly damaging neutron economy. Concepts such as the "diabolo" design with an axially shorter central core region show great promise [8] [9] [10]. The heterogeneous core design approach is a possible way for eliminating positive coolant density reactivity feedback but results in a large penalty on the neutron economy and, likely, on the reactor economic viability, while complicating the fuel fabrication and fuel management. The approach fails criteria C1, D1 and D2 in Table 1. Just as for GEMs, the method is only effective enough to abide by the Category A criteria if it fails criteria B2.

\section{Moderation based solutions}

Introducing moderators leads to improved reactivity feedback at the cost of spectral softening and neutron economy impairment in standard operation. This approach fails to pass the B1 criteria of Table 1 by definition, while, depending on the specifics of the moderator-type, the B3 criterion may be failed as well.

\section{Solid absorbers}

Solid absorbers that preferentially absorb high-energy neutrons can improve feedback but absorbs a significant fraction of the available neutrons also during normal operation. It fails the B3 criteria of Table 1 by definition, while, depending on the specifics of the absorber-type, the B2 criterion may be failed as well. 
The reactivity worth of the in-core solid absorbers will decrease over time, which means a conditional fail on criteria A6.

\section{Liquid absorber based solutions}

\subsection{Introduction}

Liquid absorber systems have the potential to be inserted into the active region of the core as the coolant temperatures increases and retracting from the active core region as temperatures decrease. While conceptually highly promising, the challenge has been to find a viable engineering implementation for a liquid-based absorber system. Two methods that have been devised to date are presented below.

\subsection{TWR thermo-stat modules}

The use of ${ }^{6} \mathrm{Li}$ for reactivity control was introduced along with the original travelling wave reactor (TWR) design by Teller et. al [11]. Lithium has several unique properties that make it suitable for reactivity control. Natural lithium consists of $92.5 \%{ }^{7} \mathrm{Li}$ and $7.5 \%{ }^{6} \mathrm{Li}$. ${ }^{7} \mathrm{Li}$ is neutronically benign while ${ }^{6} \mathrm{Li}$ is a very potent neutron poison with a high absorption cross-section also at high neutron energies. Isotopic separation of the lithium isotopes is relatively inexpensive, and lithium stays liquid throughout sodiumcooled reactor operating temperature regimes. Because of this, lithium has been the focus of at least two innovative passive reactivity control systems. The system devised by Teller et. al. [10] for the TWR consists of two connected metallic compartments, one filled with ${ }^{6} \mathrm{Li}$ and the other with ${ }^{7} \mathrm{Li}$, fed by capillary tubes. The ${ }^{7} \mathrm{Li}$, which is permanently located within a compartment in the fuel region, expands upon a temperature increase, which in turn actuates a piston that injects ${ }^{6} \mathrm{Li}$ into a separate compartment located inside a coolant channel. When temperatures decrease, the ${ }^{6} \mathrm{Li}$ retracts down a tube and leaves the in-core compartment. In this way, a passive thermo-stating reactivity control system with negligible impact on core neutronics during standard operation was devised. The system is shown in Figure 5. 


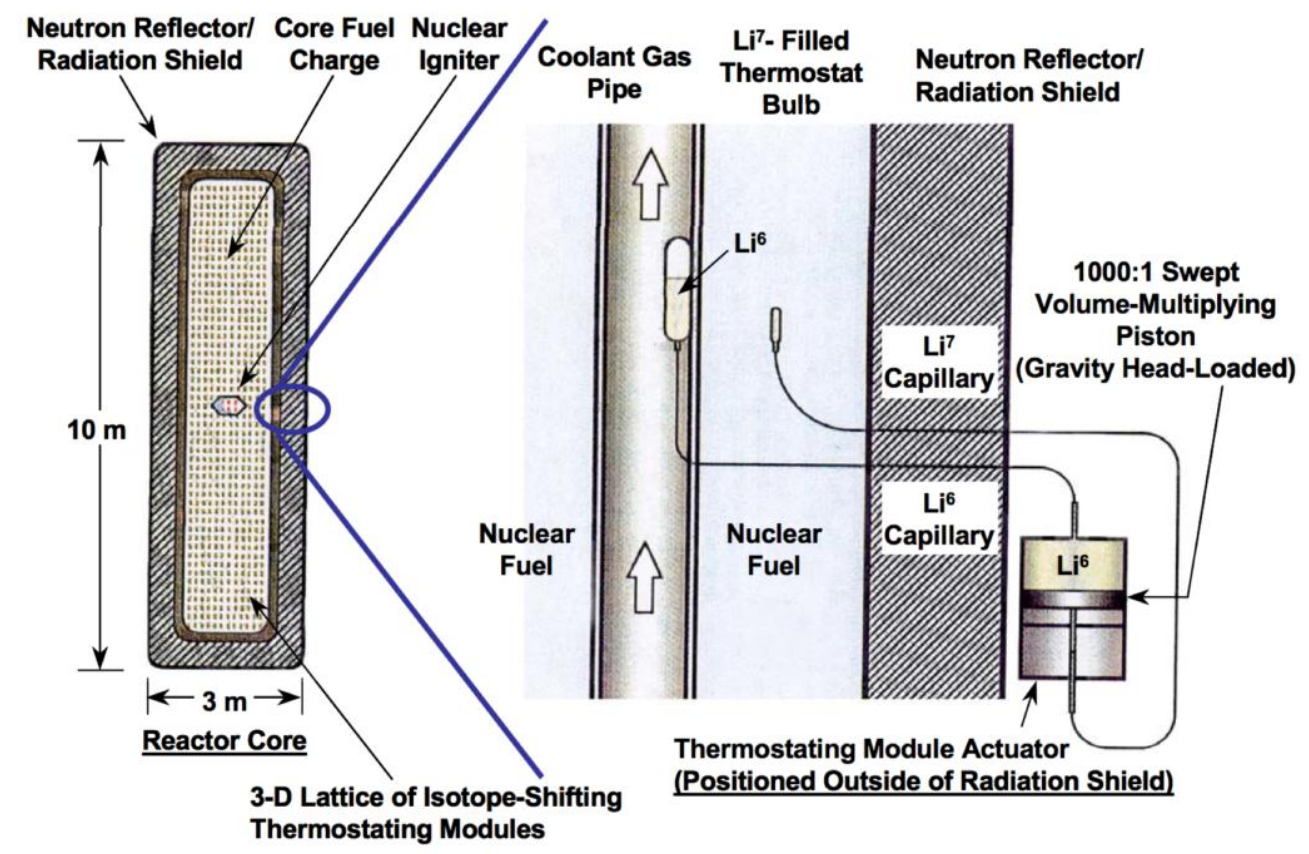

Figure 5, The TWR ${ }^{6} \mathrm{Li}$ thermo-stating control system [11]

The system characteristics are optimal for a neutronically efficient fast reactor core, however the proposed specific engineering implementation does not work in a system requiring fuel shuffling. Also, the system function cannot be said to inherently safe in the strictest sense; it relies upon the proper functioning of thousands of moving mechanical parts (pistons) with an assigned failure probability, rather than simply on natural laws and phenomena. Since the system is both distributed and highly redundant, this is a minor issue.

The TWR thermo-stat module is an innovative and ingenious solution for improving fast reactor reactivity feedback. It does not impact the core at all during standard operating conditions but adds a large amount of negative reactivity in the event of an accident. It is however quite a complicated mechanical system with moving mechanical parts and thousands of pipes ${ }^{1}$ entering and leaving the core. It fails criteria A4, $\mathrm{C} 1$ and E6 of Table 1. The failure of criteria A4 also lead to a conditional fail of criteria A6.

\subsection{Lithium expansion modules (LEM)}

In 1998, Kambe et. al developed the Lithium Expansion Module (LEM) system for reactivity control for the RAPID cores [12]. LEMs consist of one or more large reservoirs of ${ }^{6} \mathrm{Li}$ located above the core, with close-ended tubes leading down through the active core region. During standard operation, the ${ }^{6} \mathrm{Li}$ in the tubes is suspended above the active core by argon gas. When temperatures increase, the ${ }^{6} \mathrm{Li}$ inside the reservoir expands. This pushes ${ }^{6} \mathrm{Li}$ down the tube and into the core region while compressing the argon gas. LEMs can provide large amounts of negative reactivity, operate passively and do not affect core neutronics noticeably during standard operation. In addition, LEM- devices do not have any moving mechanical parts 
with associated failure probabilities. The inspiration for the ARC-systems that are presented in Section 8 and onward came from the LEM and TWR thermo-stating systems. The operation of a LEM-device installed in a sodium cooled fast reactor is shown in Figure 6.

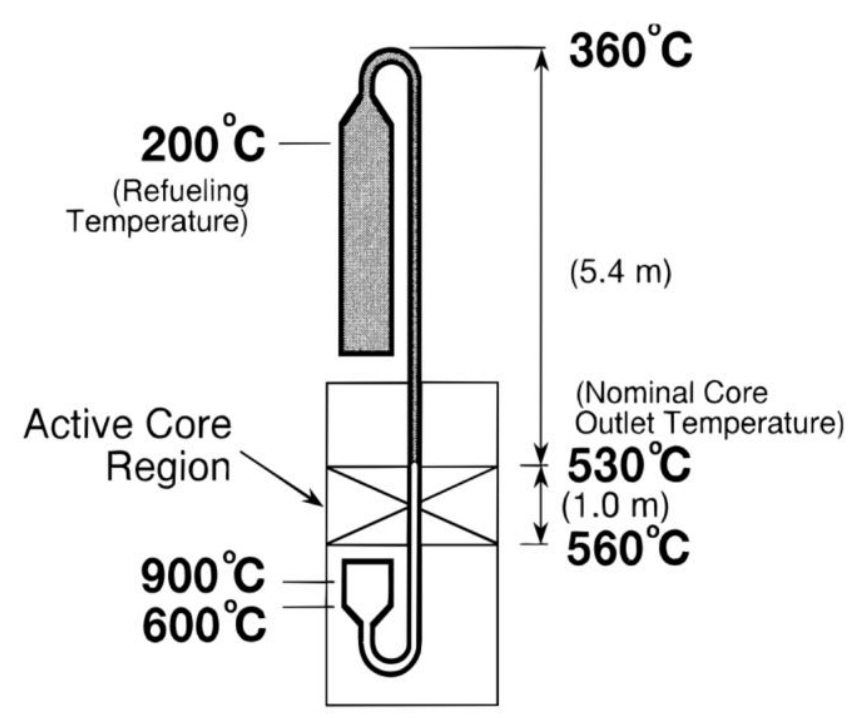

Figure 6, Lithium expansion module $(\mathrm{LEM})$ operation $\left(\right.$ Grey $=$ Liquid ${ }^{6} \mathrm{Li}$, White $=$ Argon $)[12]$

While LEM-systems are the most promising existing option analyzed, they have a number of drawbacks that are not immediately obvious. The installation approach as given in ref. [12] effectively makes conventional fuel shuffling operations difficult. The proposed method is to remove the entire LEM-system from the core and hang it from a support in the upper internal structure as the fuel is being shuffled or added/removed from the core. While this is conceivable, it may be quite a difficult operation in the opaque environment of a liquid metal cooled reactor. The LEMs are located axially above the core in a low neutron flux. However, the rather large volume of highly enriched lithium will inevitably see a continuous finite flux, causing (primarily) the following reaction:

$$
{ }^{6} \mathrm{Li}+n \rightarrow{ }^{4} \mathrm{He}+{ }^{3} H
$$

Severe accident-scenarios causing actuations can reasonably be assumed to occur seldom enough to have a negligible impact on the material composition of the LEM reservoir. Careful shielding design must ensure that the axially leaking neutron flux is sufficiently low as to not impact the long-term performance of the LEM-reservoirs. The main issue with LEM-systems however is that of criteria A2 (the risk of positive reactivity insertion). If the gas/liquid interface breaks during full actuation of the system, gas bubbles will travel axially upwards through the highest worth regions of the core, producing a positive reactivity insertion matching the negative reactivity introduced during its actuation. Uncertainties in the stability of the gas/liquid interface and the potential of positive reactivity insertions make the licenseability of the systems questionable. 
LEMs operate completely passively, have no moving parts and provide strong negative feedback during accidents while having a negligible impact on the core in standard operation. The only major drawbacks of the system are the large inventory of ${ }^{6} \mathrm{Li}$ and the potential for a positive reactivity insertion. LEMs directly fail criteria A2, and conditionally fail criteria A6, C1 and E5.

\subsection{Flow levitated absorbers}

Flow levitated absorbers (FLAs) consists of balls or plates held in a separate assembly at or just above the axial level of the top of the active core by the coolant flow. As the coolant flow decreases in a loss-of-flow event, the absorbers drop in to the core causing a negative reactivity insertion [13]. FLAs can be placed anywhere in the core and only cause a minor negative impact on the neutron economy during standard operation. They fail criteria A7 (only responding to LOF), C2 and E6 of Table 1. As with all absorber systems, criterion A6 is conditionally failed.

\subsection{Enhanced control rod driveline expansion systems (ECRDL)}

Efforts have been made to design passive systems that increase the expansion of standard reactor control rods in to the core upon coolant temperature increases [14]. The reactivity worth of the ECRDL systems are directly linked to the control rod worth. Breeder cores with low burnup reactivity swing have rather low worth vested in control assemblies (which helps to reduce the consequences of UTOP events), which means that ECRDL systems in such cores would be comparatively ineffective. The ECRDL systems fail criteria A4 and E5 of Table 1.

\section{Summary evaluation of existing solutions}

A summary of the drawbacks of the systems presented in Section 6, as defined by the evaluation criteria of Table 1, is given in Table 2 .

Table 2, Summary evaluation of reactivity feedback improvement approaches

$\begin{array}{llll}\text { ID\# } & \text { Solution approach } & \text { Direct fail } & \text { Conditional fail } \\ 1 & \text { H/D reduction } & \text { B2, D1, D2 } & - \\ 2 & \text { Gas expansion modules (GEM) } & \text { A2, A7, C2 } & \text { B2 } \\ 3 & \text { Heterogeneous core design } & \text { C1, D1, D2 } & \text { B2 } \\ 4 & \text { Moderation based solutions } & \text { B1 } & \text { B3 } \\ 5 & \text { Solid absorbers } & \text { B3 } & \text { B2, A6 } \\ 6 & \text { TWR thermo-stat } & \text { A4, C1, E6 } & \text { A6 }\end{array}$




$\begin{array}{llll}7 & \text { Lithium expansion modules (LEM) } & \text { A2 } & \text { A6, C1, E5 } \\ 8 & \text { Flow levitated absorbers (FLA) } & \text { A7, C2 } & \text { A6, E6 } \\ 9 & \text { Enhanced CRDL expansion } & \text { A4, E5 } & \text { E6 }\end{array}$

No generalized "ranking" of the different approaches can be extrapolated from Table 2, but some interesting conclusions can be drawn. There are only 4 approaches that can significantly improve the inherent safety of a fast reactor without themselves impairing the neutron economy or requiring a highleakage core to begin with. These solutions, \#6-9 of Table 2, are all based on the inherent and passive movement of strongly absorbing material in and out of the active core. Out of these 4 solutions, only the LEM system, which does not involve any movement of solid materials, fully passes criteria E6. It was realized that if a movable liquid-absorber type of system could be designed free of a failure mode that introduces positive reactivity (criteria A2); a solution that does not directly fail any of the criteria of Table 2 could be found. This was the starting point for the development of the Autonomous Reactivity Control (ARC) system, presented in the following section. 


\section{The Autonomous Reactivity Control (ARC) system design}

The ARC system is based on the idea of having a separate liquid (or gas) push a neutron-absorbing liquid in to the core in the event of a deviation from nominal operating conditions, rather than having the absorber liquid expand itself in to the core as in a LEM (see Section 6.3). Furthermore, the system should be designed in a way that requires a minimal change to a conventional fast reactor fuel assembly and core design. The injection of absorber liquid should be spatially distributed in the core, which can be done through one or more emptied out fuel rods within the fuel assemblies themselves. The total system inventory of neutron absorber liquid should be not much greater than what is needed in the active core at full actuation. If a system with these characteristics could be designed, it would have some important advantages over LEMs:
a. No reliance on a gas/liquid interface (which is the reason why LEMs fail criteria A2)
b. Greatly reduced inventory of neutron absorber/poison
c. Increased system stability and redundancy
d. Reduced implementation costs

The idea is illustrated in Figure 7 and Figure 8; it has an upper liquid reservoir at the top of the fuel assembly filled with a neutronically transparent liquid that is immiscible with lithium. As temperatures rise from some reference operating state, a small pipe inside a larger pipe communicates the volumetric expansion of the upper liquid (henceforth: the expanding liquid) to a compartment below the core. The lower compartment contains a dual-layer of liquids, with the absorbing liquid floating on top of the expanding liquid. Axially above the dual-layered liquids (in the axial region of the active core) is an inert gas such as argon. As the liquid in the reservoir expands, the upper axial level of the absorbing liquid rises (while compressing the gas) and enters in to the volume between the inner and outer pipe and rises in to the axial region of the active core from below. When temperatures drop again, the system will re-equilibrate, in a similar manner to a LEM, to its initial state. In such a way, the system avoids the use of a gas/liquid interface and only needs a small amount of neutron poison. The specifics of the ARC-LL system installation are dependent on the specifics of the overall core design. Most important is whether the core design primarily uses an upper or lower fission gas plenum. For cores with a lower gas plenum, there is enough room below the core to install the "lower ARC reservoir" component completely seamlessly within the rods themselves. The system and its components, as installed in conventional fast reactor fuel assemblies with lower and upper fission gas plena are shown in Figure 7 and Figure 8 respectively. The expanding liquid is green, the neutron absorbing poison is red and blue represents an inert gas. The figures show the systems as they appear at refueling temperatures. A full 3-dimensional model of the system without fuel rods and with a single ARC-pin was developed in AutoCAD and is shown in Figure 9. 


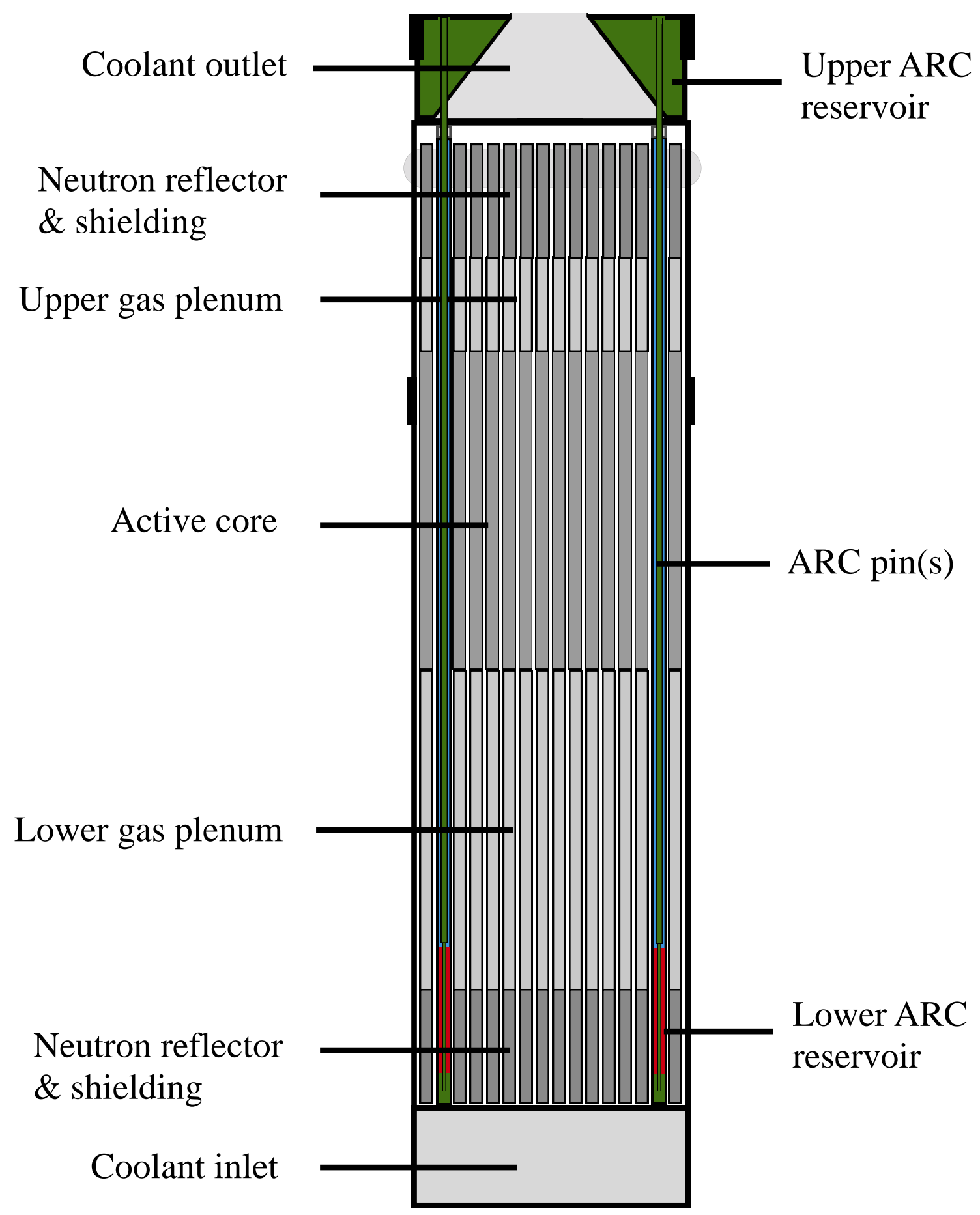

Figure 7, The ARC-LL fuel assembly system design with 2 fuel rods replaced by ARC-tubes for a lower fission gas plenum core 


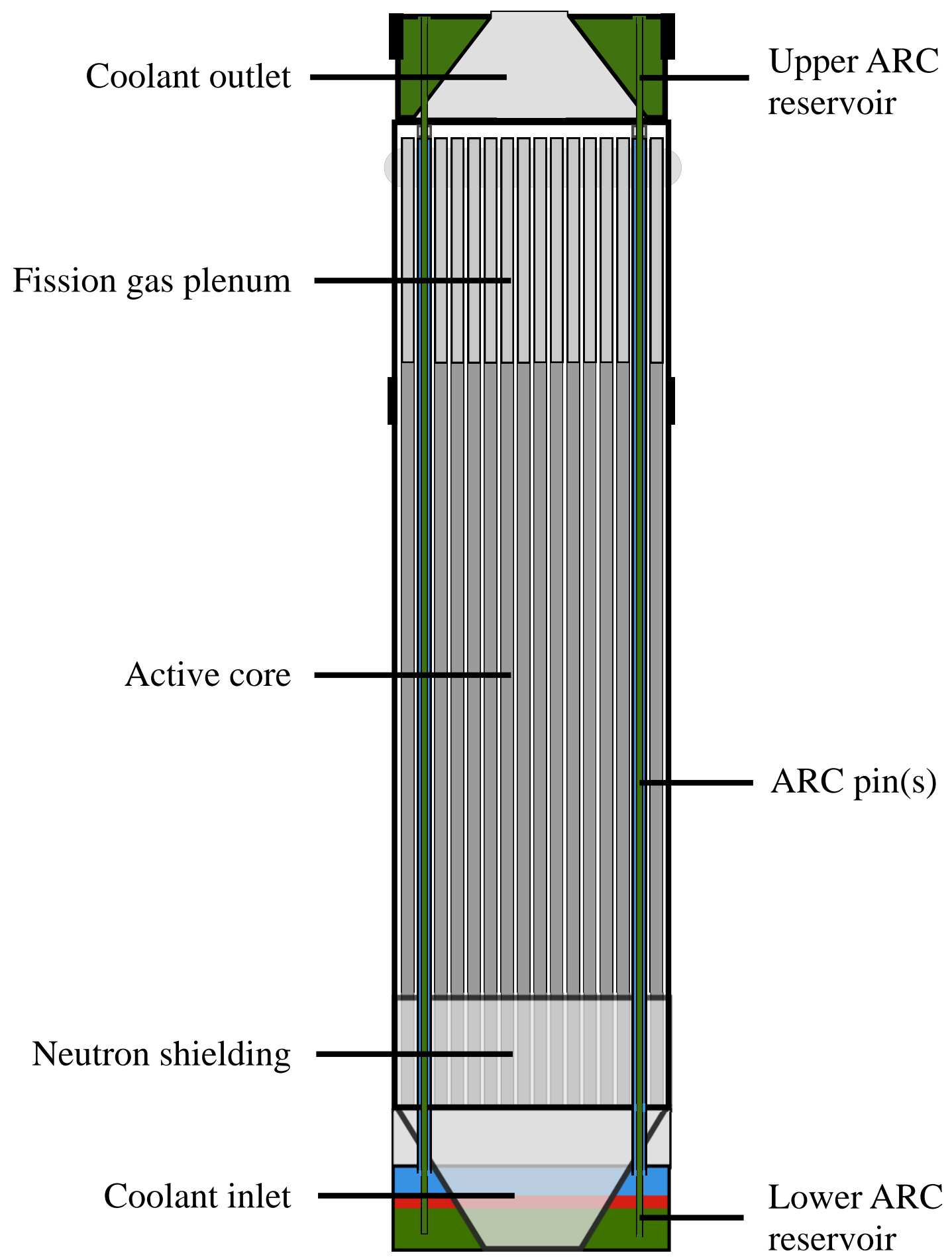

Figure 8, The ARC-LL fuel assembly system design with 2 fuel rods replaced by ARC-tubes for an upper fission gas plenum core 


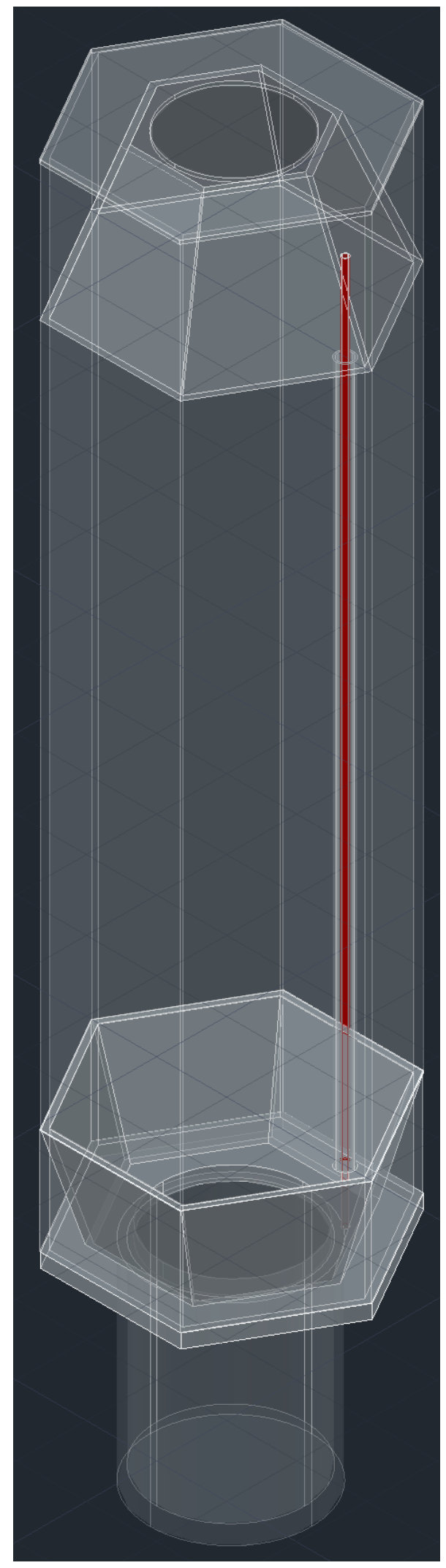

Figure 9, 3D CAD-model of an assembly with a single ARC-pin (inner ARC-tube is shown in red) 
Details of the upper ARC-reservoir, common for both lower and upper and lower gas plena designs, are shown in Figure 10. The coolant outlet temperature directly controls the temperature of the expanding liquid inside the upper reservoir. As temperatures increase, thermal expansion causes the liquid to increase in volume. Since the upper reservoir is already completely filled, this expansion is directed down the inner ARC-tube. The inner tube is open to the reservoir at the very top in order to minimize the gravity head of liquid that the inert gas between the inner and outer ARC tubes need to counter-act.

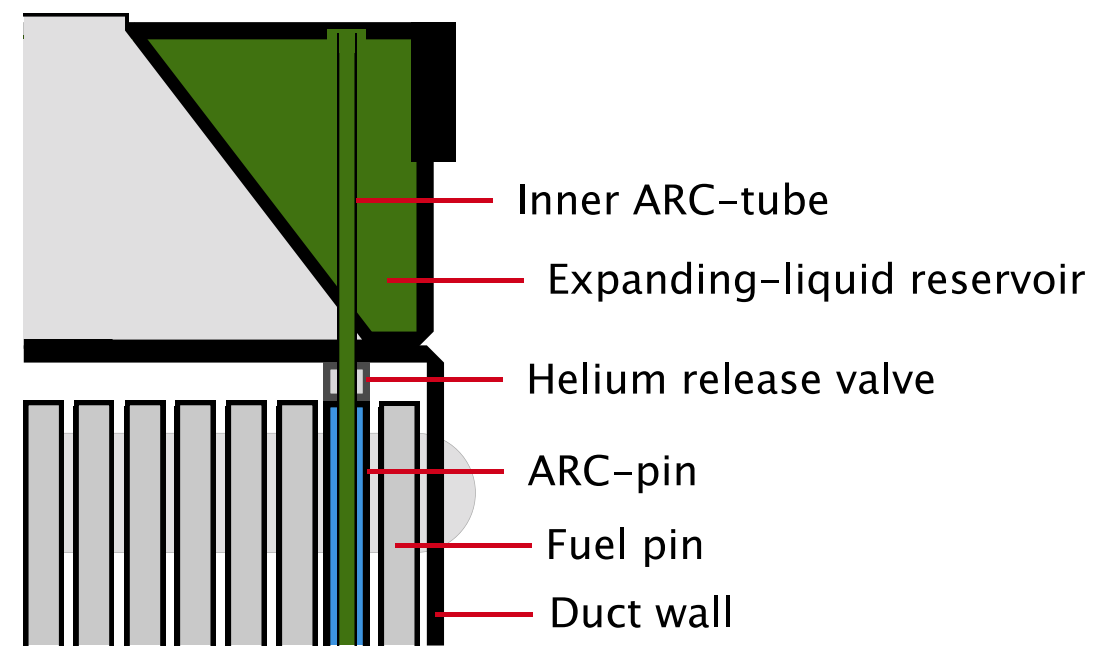

Figure 10, Upper ARC-LL reservoir installation

The expansion of the upper ARC reservoir liquid thus communicates changes in the coolant outlet temperature directly to the lower reservoir. The design and state of the lower ARC reservoirs for lower and upper gas plena cores at refueling temperatures are shown in Figure 11.
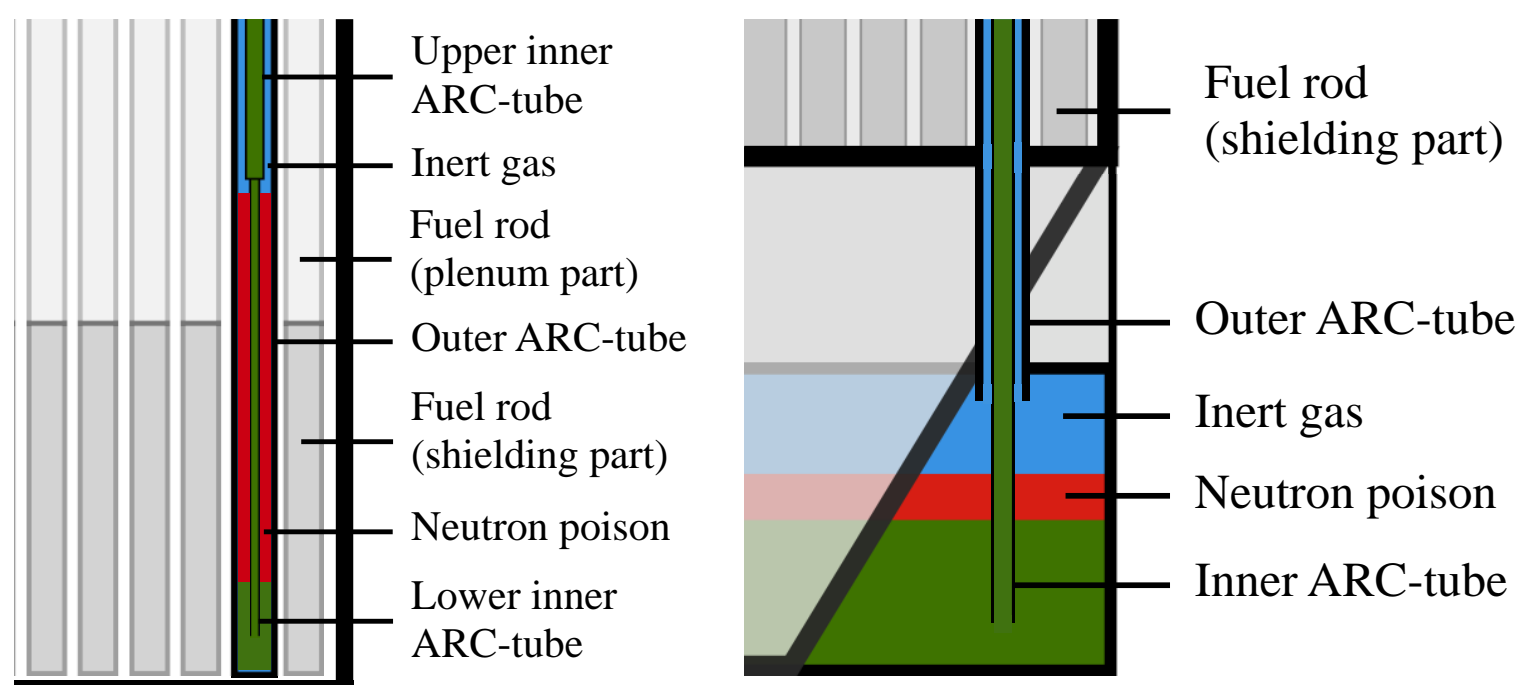

Figure 11, Lower ARC reservoirs for lower gas plenum (left) and upper gas plenum (right) cores 
One of the challenges in designing the ARC-components is to accommodate the large temperature range over which the system needs to function. It is not only the expansion between standard operating temperatures and elevated temperatures in an accident that is of importance, but also the expansion of the liquids going from refueling temperatures up to operating temperature. The various states of actuation for both system versions, zoomed in at the lower reservoir part, are shown in Figure 12.

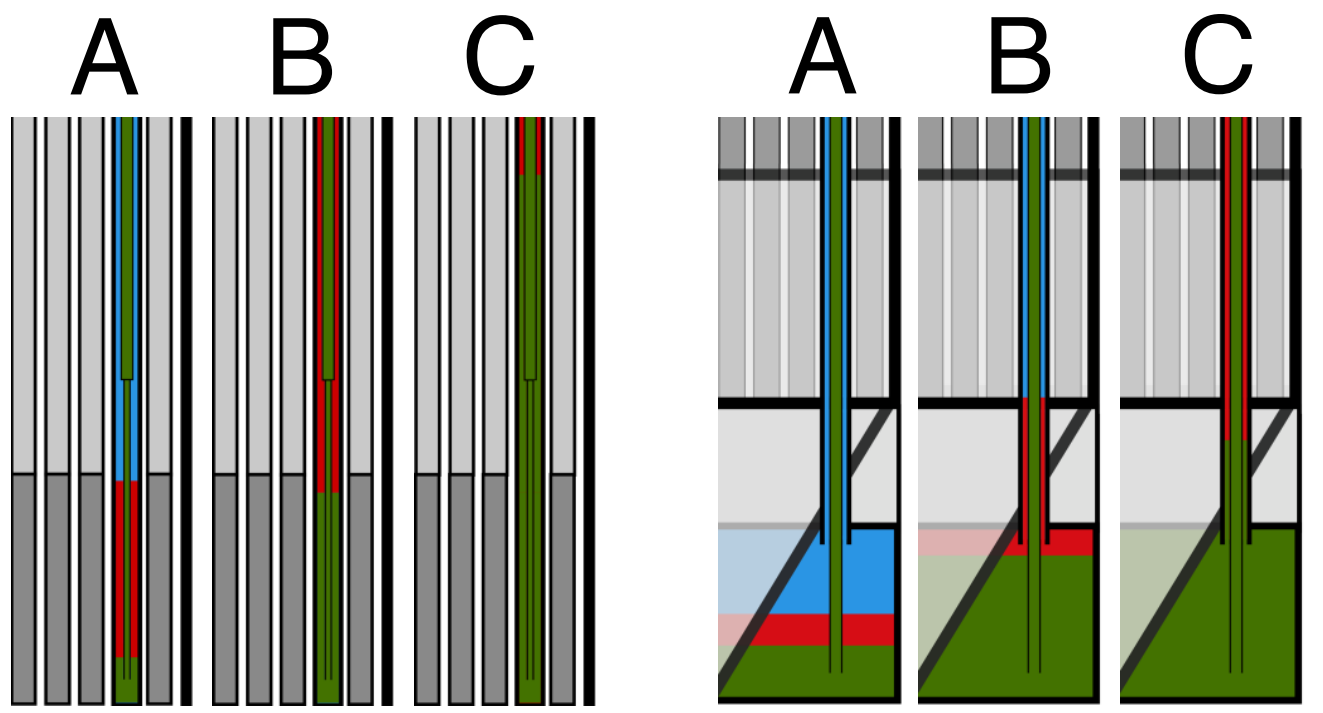

Figure 12, States of actuation of a lower (left) and upper (right) gas plenum core ARC installation $\mathrm{A}=$ Refueling, $\mathrm{B}=$ Standard operation, $\mathrm{C}=$ High temperature transient.

At standard operation, the top axial level of the absorbing liquid needs to be set at a carefully defined level which is below the active core. This level is given by the "optimal" balance between limiting the flux exposure of the absorbing liquid during standard operation while at the same time ensuring a rapid injection in to the active core during accidents. The remaining volume available for free expansion of the liquids of the ARC system at standard operation, taken up by an inert gas, is what determines the total volume of expansion liquid in the system. Error! Reference source not found. describes the volume balance of the liquids in the system.

$\left[V_{\mathrm{e}}\left(T_{\text {actuation }}\right)-V_{\mathrm{e}}\left(T_{\text {operation }}\right)\right]+\left[V_{\mathrm{p}}\left(T_{\text {actuation }}\right)-V_{\mathrm{p}}\left(T_{\text {operation }}\right)\right]=V_{\text {ARC }}$

Where $\mathrm{V}$ is the total component volume, $e$ denotes the expanding liquid, $p$ is the neutron poison (absorbing liquid) and $\mathrm{V}_{\mathrm{ARC}}$ is the total volume between the inner and outer ARC tubes from the axial level of the neutron poison at operation temperature to the top of the active core region.

The area ratio between the inner and outer ARC-tubes determines both the reactivity worth and the relative speed of actuation of the ARC-pin. This makes it possible to design a sequential system with fast acting 
low-worth pins and slower acting high worth pins. A top-view of the ARC-LL fuel assembly design with such a system is given in Figure 13.

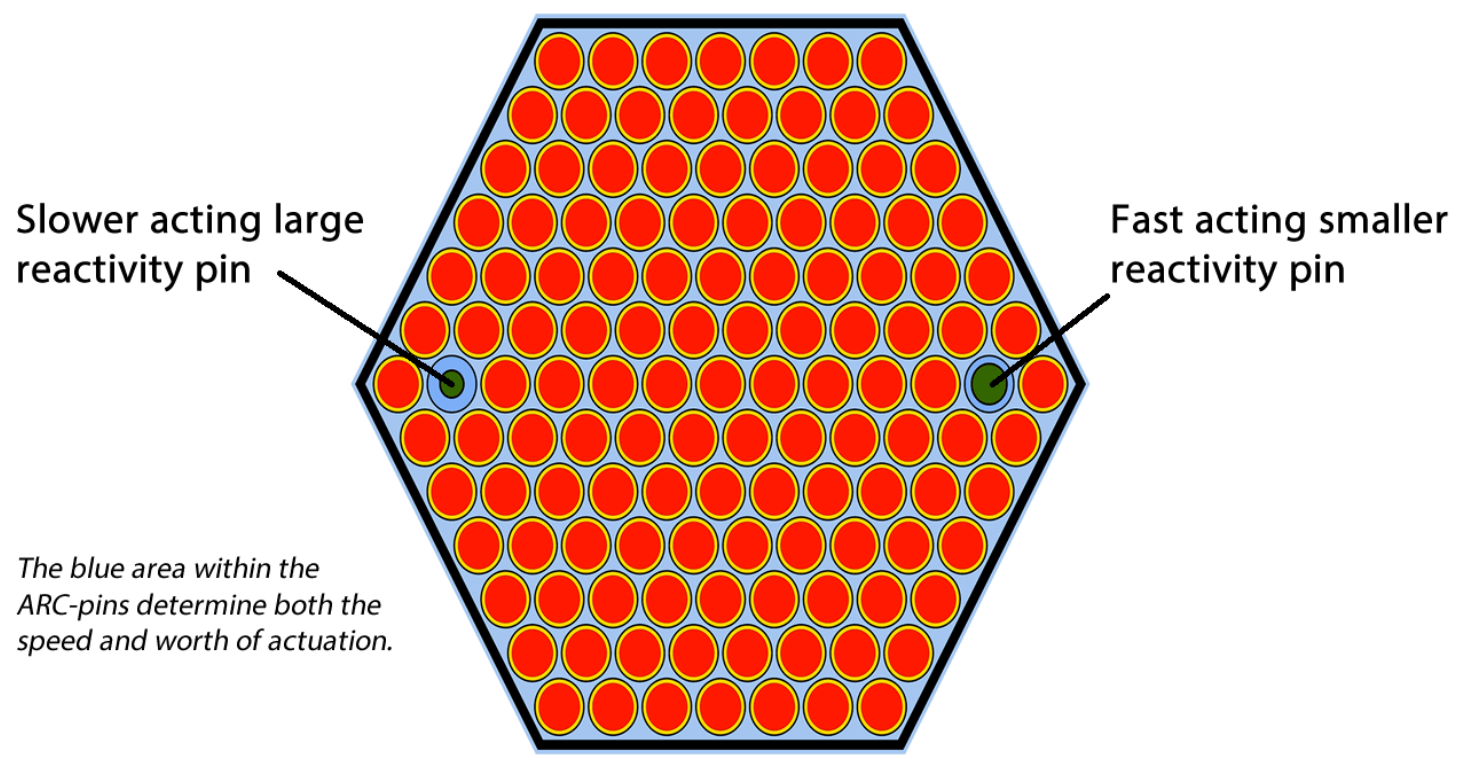

Figure 13, Fuel assembly installation of an ARC system

The required volume available in the lower reservoir is determined by the volumetric increase of the expanding and absorbing liquids going from refueling/shutdown temperature of the core up to standard operating temperatures.

$$
\begin{aligned}
V_{\mathrm{LR}}= & {\left[V_{e}\left(T_{\text {operation }}\right)-V_{e}\left(T_{\text {refueling }}\right)\right]+\left[V_{p}\left(T_{\text {operation }}\right)-V_{p}\left(T_{\text {refueling }}\right)\right] } \\
& +V_{\text {foot }}\left(T_{\text {operating }}\right)
\end{aligned}
$$

in which $\mathrm{V}_{\mathrm{LR}}$ is the volume of the lower $\mathrm{ARC}$ reservoir and $\mathrm{V}_{\text {foot }}$ is the volume of expansion liquid that is always required in the lower reservoir to ensure that the axial level of the liquid/liquid interface level stays above the inner ARC tube opening in the lower reservoir. The design of the ARC system is constrained by the requirement of fulfilling both Error! Reference source not found. and Error! Reference source not found.. The starting point for the ARC system design is determining the needed feedback, as measured in added negative reactivity worth over a set increase in coolant outlet temperature. Approaches to determine system response are discussed in the following section.

\section{Determining the ARC system reactivity response}

The ARC system can be designed to address one of the following three reactivity response strategies:

S1. A system response-speed and worth that ensures that temperatures stay below safety margins during severe unprotected accident scenarios such as ULOF, ULOHS and UTOP. 
S2. A system worth and response-speed that matches the positive single-phase coolant temperature reactivity feedback

S3. A system worth that gives a negative core reactivity state at an average core temperature corresponding to full coolant voiding

The requirements for total size and worth of the ARC-systems increases dramatically going from S1 to S3. Analyzing and finding the ARC-design corresponding to $\mathrm{S} 1$ is preferable, as it gives the minimal possible intrusion to the standard fuel assembly design and is therefore optimal for the neutron economy. A reliable and licensable assessment of a system corresponding to strategy S1 is however very complicated and requires the use of a transient systems code such as SAS4A/SASSYS-1 [15]. Modeling work for the ARC system in SAS4A/SASSYS-1 is currently being carried out at University of California Berkeley in collaboration with the Royal Institute of Technology, Stockholm, Sweden [16]. S2 is a less precise method, attempting to match both in time and worth the only ${ }^{2}$ positive reactivity feedback in the core. Coolant density reactivity in single-phase is nearly linear, while the ARC-system response worth is highly nonlinear. Because of this, an S2-type system will have a defined temperature increase at which point the ARC-system matches, and then dominates over the coolant density feedback. S3 only applies to sodiumcooled reactors as total coolant voiding by boiling in lead and LBE-cooled cores occurs at temperatures far higher than the melting point of the structural materials in the core. Sodium loses about $12 \%$ of its density as a single-phase liquid going from a nominal core average temperature of $450^{\circ} \mathrm{C}$ to the boiling temperature. The remaining $\sim 88 \%$ is lost in the phase-transition. Correspondingly, there is a large discontinuity in the temperature reactivity feedback of the coolant when boiling occurs. During voiding by boiling, $\sim 9 \mathrm{x}$ as much reactivity is added as during the $\sim 400^{\circ} \mathrm{C}$ rise of the single-phase coolant temperature needed to reach boiling. This is the reason for the strong focus of sodium fast reactor designs to avoid voiding events. If the full actuation-worth of the ARC-system matches that of the positive reactivity insertion of complete coolant voiding and reaches this state at a time and temperature before boiling occurs, such a system could provide a type of "ultimate" safety. In any real anticipated situation, such a system would completely shut off the fission process and bring temperatures down (assuming proper thermalhydraulic design) long before voiding actually occurs.

\section{Materials selection}

The reference neutron poison for the ARC system is liquid lithium, enriched in the ${ }^{6} \mathrm{Li}$ isotope to a level to be determined in the design optimization process. The fast spectrum neutron absorption cross-section of ${ }^{238} \mathrm{U}$ (which in many systems is the primary neutron absorber) and the (n, $\alpha$ ) cross-section of ${ }^{6} \mathrm{Li}$ are shown in Figure 14. The average neutron energy in a liquid-metal cooled fast reactor core is in the range 200-400 $\mathrm{keV}$, making ${ }^{6} \mathrm{Li}$ a very potent fast core neutron poison. 


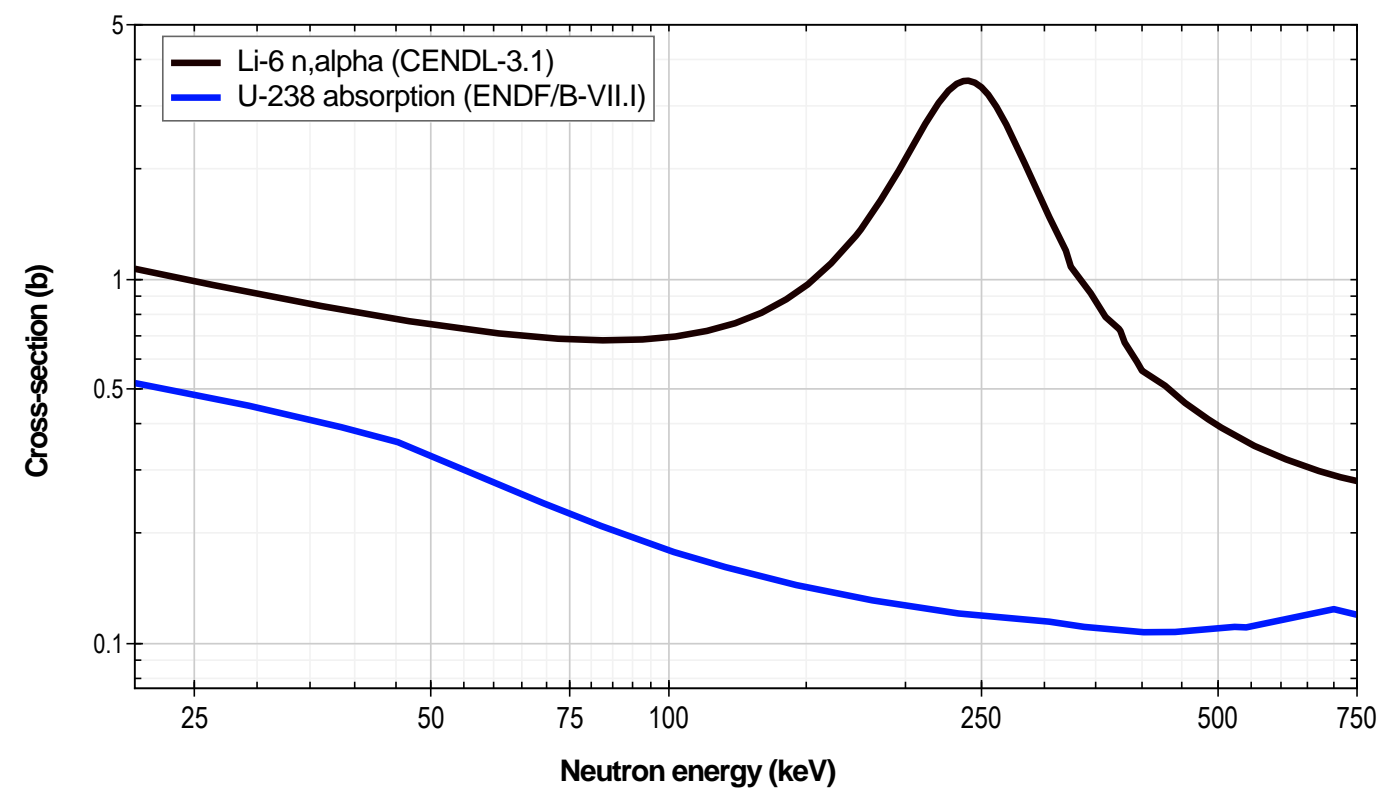

Figure $14,{ }^{6} \mathrm{Li}(\mathrm{n}, \boldsymbol{\alpha})$ and ${ }^{238} \mathrm{U}(\mathrm{n}, \gamma)$ neutron cross-sections in the keV energy range

An extensive search was undertaken for the expanding liquid, including a detailed analysis of over 40 elements, compounds and alloys. The requirements for the expanding liquid are summarized in Table 3. These requirements are ordered in two categories by importance, with category-A denoting strict requirements and $\mathrm{B}$ offering criteria to select between material options that adhere to the requirements of A1-A7.

Table 3, ARC expanding liquid requirements \& evaluation criteria

\begin{tabular}{ll}
\hline Req. ID\# & Description \\
\hline A1 & Liquid range of at least $200^{\circ} \mathrm{C} \leq \mathrm{T} \leq 650^{\circ} \mathrm{C}$ \\
A2 & Very low solubility or (preferably) completely immiscible with lithium \\
A3 & Non-corrosive to steel \\
A4 & Low neutron absorption cross-section \\
A5 & Not prohibitively expensive \\
A6 & Chemically stable under irradiation \\
A7 & Chemically compatible with liquid metal coolants \\
\hline B1 & Large thermal expansion coefficient \\
B2 & Small volume change upon phase change \\
B3 & High boiling point $\left(\mathrm{T}_{\text {boil }} \geq 700^{\circ} \mathrm{C}\right)$
\end{tabular}

The search yielded 4 pure element alternatives that could possibly work as the expanding liquid. The relevant data to assess the viability of the different options are summarized in Table 4 . A $50^{\circ} \mathrm{C}$ margin to 
phase-change (boiling) was imposed on the temperature ranges for calculating volumetric expansion. Production, availability and cost data are from reports published in 2010 that are cited in the table.

Table 4, Relevant properties of elemental ARC expanding liquid alternatives

\begin{tabular}{|c|c|c|c|c|}
\hline Parameter & Cesium & Indium & Potassium & Rubidium \\
\hline Melting temperature & $28^{\circ} \mathrm{C}$ & $157^{\circ} \mathrm{C}$ & $63^{\circ} \mathrm{C}$ & $39^{\circ} \mathrm{C}$ \\
\hline Boiling temperature & $671^{\circ} \mathrm{C}$ & $2072^{\circ} \mathrm{C}$ & $759^{\circ} \mathrm{C}$ & $688^{\circ} \mathrm{C}$ \\
\hline Corrosivity & Acceptable [17] & Low $[\mathbf{1 8}]$ & Very low [19] & Low $[\mathbf{2 0}]$ \\
\hline Li solubility & None [21] & 1 at. $\%$ [22] & < 4 wt. ppm [23] & None [24] \\
\hline Neutron abs. XS & High & Very high & Very low & Low \\
\hline Price/kg & $\$ 47800[25]$ & $\$ 571[26]$ & $\$ 20$ [27] & $\$ 52300[\mathbf{2 8}]$ \\
\hline Production / year & $\mathrm{n} / \mathrm{a}$ & 640 [29] & $>30000[27]$ & $\mathrm{n} / \mathrm{a}$ \\
\hline World reserves (MT) & $>7000[\mathbf{3 0}]$ & $6000[31]$ & $>8 \times 10^{9}[27]$ & $\mathrm{n} / \mathrm{a}$ \\
\hline $\begin{array}{l}\text { Expansion temperature } \\
\text { range }\end{array}$ & $500-620^{\circ} \mathrm{C}$ & $500-700^{\circ} \mathrm{C}$ & $500-700^{\circ} \mathrm{C}$ & $500-630^{\circ} \mathrm{C}$ \\
\hline $\begin{array}{l}\% \text { vol. expansion in } \\
\text { temperature range }\end{array}$ & $4.5[32]$ & $2.3[33]$ & $6.9[34]$ & $4.9[35]$ \\
\hline
\end{tabular}

All the 4 elements of Table 4 have liquid lithium solubility low enough to ensure stable stratification.

Based on the low boiling temperature and general material unavailability, Cesium and Rubidium were not chosen for detailed study. Indium is available commercially in large quantities and has the most favorable temperature range for single-phase operation. The much higher relative volumetric expansion coefficient of potassium, lower cost and most significantly; far lower one-group fast spectrum neutron absorption crosssection, make it a superior option. Potassium is the preferred choice for the expanding liquid for ARC system. The summary evaluations of the candidate materials are given in Table 5.

Table 5, Candidate material ARC expansion liquid criteria evaluation

\begin{tabular}{lllll}
\hline Req. ID\# & Cesium & Indium & Potassium & Rubidium \\
\hline A1 & Pass & Pass & Pass & Pass \\
A2 & Pass & Pass & Pass & Pass \\
A3 & Pass & Pass & Pass & Pass \\
A4 & Fail & Fail & Pass & Pass \\
A5 & Fail & Pass & Pass & Fail \\
A6 & Pass & Pass & Pass & Pass \\
A7 & Pass & Pass & Pass & Pass \\
\hline B1 & Pass & Fail & Pass & Pass \\
B2 & Pass & Pass & Pass & Pass
\end{tabular}




\begin{tabular}{lllll} 
B3 & Fail & Pass & Pass & Fail \\
\hline Sum of fails & 3 & 2 & 0 & 2
\end{tabular}

\section{ARC system design methodology}

A simplified view of the ARC system design strategy is given in Figure 15. After deciding upon the reactivity response strategy (see Section 9), the reactivity worth characteristics of the ARC-system need to be determined using neutron transport calculations. The details of estimating the worth characteristics are given in Section 12. The peak pressure differential across the inner and outer ARC-tube walls needs to be calculated in order to estimate the required thickness of these tubes. This involves calculating the internal gas pressure needed to counteract gravity and bring the system absorber liquid level down from full actuation back to its shutdown level. With this information and Error! Reference source not found. \& Error! Reference source not found., it is possible to design a full ARC-installation.

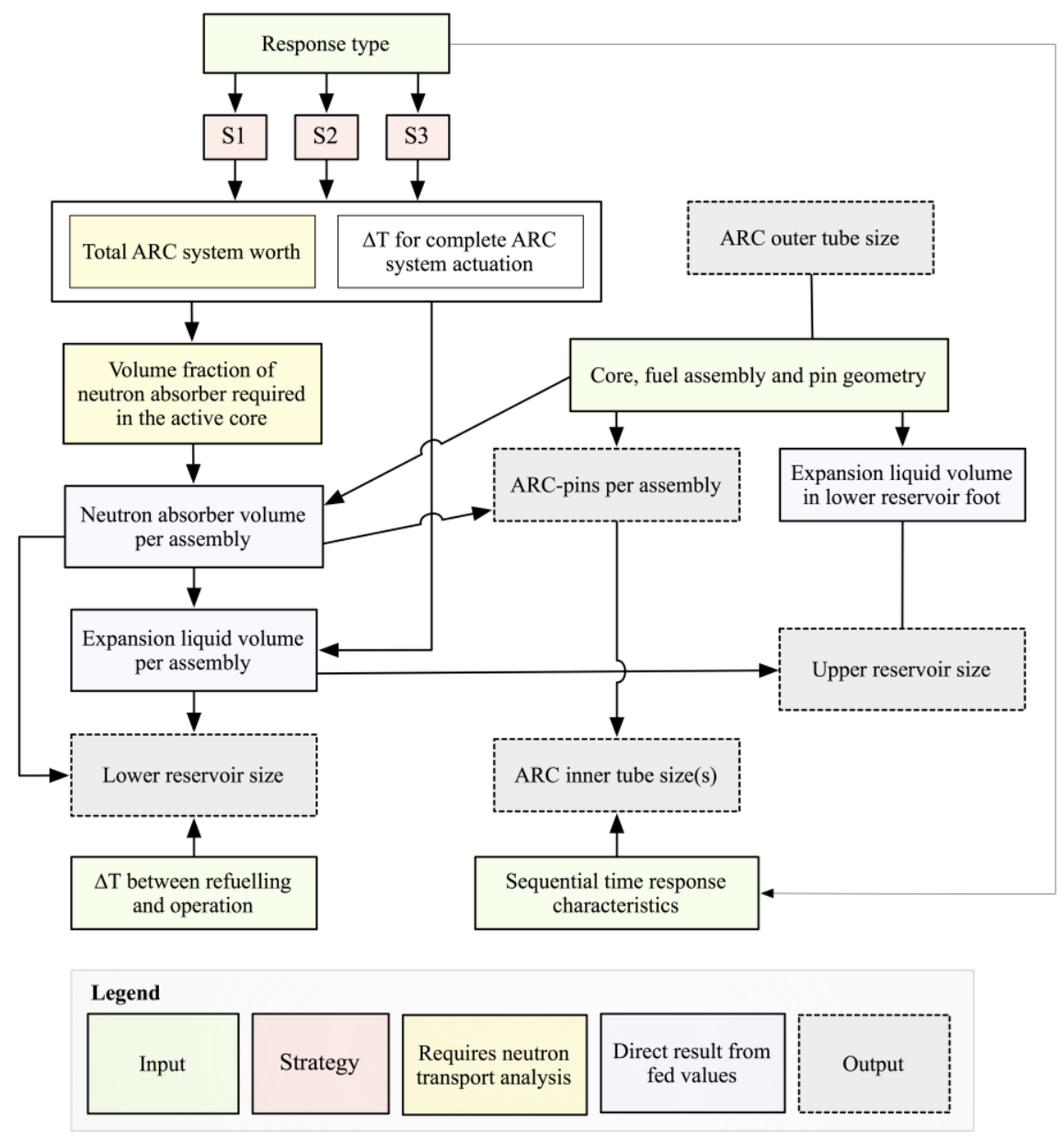

Figure 15, Design flow-chart for an ARC-system 


\section{Example ARC system for compensating total core voiding ( $\mathrm{S3}$ response) in a large fast core}

The S3 strategy is used as an example of how to design and implement an ARC system, and at the same time to give an indication of the upper bound maximum impact an ARC-installation can have on core performance. A simple model of a large, metallic-fueled sodium cooled core was developed using the ADOPT core design code [36] and implemented in the Serpent neutron transport code for this analysis [37]. The analysis was performed using ENDF/B-VII.0 [38] neutron cross-sections and $15 \times 10^{6}$ neutron histories per simulation. The general and specific parameters of the core, without an ARC system, are summarized in

Table 6 and Table 7. For simplicity and clarity, the core was modeled as a single homogenized cell with a fresh (no fission products) fuel composition containing $8.8 \%$ LWR TRU.

Table 6, Reference core general design parameters

\begin{tabular}{|l|l|}
\hline Parameter & Value \\
\hline Power (thermal / est. electric) & $2750 \mathrm{MWt} / \sim 1100 \mathrm{MWe}$ \\
\hline Fuel material & $85.2 \mathrm{U}-8.8 \mathrm{TRU}-6 \mathrm{Zr}$ (weight \%) \\
\hline $\begin{array}{l}\text { TRU w. } \%\left({ }^{237} \mathrm{~Np},{ }^{238} \mathrm{Pu},{ }^{239} \mathrm{Pu},{ }^{240} \mathrm{Pu},{ }^{241} \mathrm{Pu},{ }^{242} \mathrm{Pu},\right. \\
\left.{ }^{243} \mathrm{Am},{ }^{244} \mathrm{Cm}\right)\end{array}$ & $4.8 / 2.3 / 47.9 / 22.5 / 10.6 / 6.5 / 3.4 / 1.5 / 0.5$ \\
\hline Fuel smear density & $75 \%$ \\
\hline Cladding \& duct material & HT9 \\
\hline Coolant & Sodium \\
\hline Active core diameter & $4.0 \mathrm{~m}$ \\
\hline Active core height & $2.0 \mathrm{~m}$ \\
\hline Coolant inlet/outlet temperature & $355 / 510{ }^{\circ} \mathrm{C}$ \\
\hline Radial reflectors & 2 rows of assemblies (70\% HT9, 30\% Na) \\
\hline Axial reflectors & $20 \mathrm{~cm}$ HT9 below core, none above core \\
\hline
\end{tabular}

Table 7, Reference core specific design and performance parameters

\begin{tabular}{|l|l|l|}
\hline \multirow{2}{*}{ Component } & Parameter & Value \\
\hline \multirow{3}{*}{ Assemblies } & \# of active fuel assemblies & 336 \\
\cline { 2 - 3 } & \# of assemblies per batch & 21 \\
\cline { 2 - 3 } & \# of fuel pins per assembly & 169 \\
\cline { 2 - 3 } & \# of in-core control assemblies & 12 \\
\cline { 2 - 3 } & Assembly pitch & $23.25 \mathrm{~cm}$ \\
\cline { 2 - 3 } & Duct wall thickness & $4.00 \mathrm{~mm}$ \\
\hline
\end{tabular}




\begin{tabular}{|l|l|l|l|}
\hline \multirow{5}{*}{ Fuel rod } & Inter-assembly gap & $4.50 \mathrm{~mm}$ \\
\hline \multirow{5}{*}{ Power density } & Fuel diameter (as fabricated) & $1.269 \mathrm{~cm}$ \\
\hline & Cladding thickness & $0.50 \mathrm{~mm}$ (vented rod) \\
\hline & Rod outer diameter & $1.565 \mathrm{~cm}$ \\
\hline & Rod pitch & $1.672 \mathrm{~cm}$ \\
\hline & Pitch-to-diameter ratio (P/D) & 1.068 \\
\hline \multirow{5}{*}{ Volume fractions } & Core-averaged linear power & $24 \mathrm{~kW} / \mathrm{m}$ \\
\hline \multirow{5}{*}{ (as manufactured, 0\% swelling) } & Axially averaged peak linear power & $51 \mathrm{~kW} / \mathrm{m}$ & \\
\hline & Specific power & $12.18 \mathrm{MW} /(\mathrm{kg}$-actinide) \\
\hline & Component & Core-ave & Fuel ass. \\
\hline & Fuel & $44.07 \%$ & $45.65 \%$ \\
\hline & Clader-assembly coolant & $8.30 \%$ & $8.60 \%$ \\
\hline & Active coolant & $6.63 \%$ & $6.63 \%$ \\
\hline & Bond & $3.83 \%$ & $3.83 \%$ \\
\hline & Control assembly internals & $19.38 \%$ & $20.07 \%$ \\
\hline \multirow{5}{*}{} & & $14.69 \%$ & $15.22 \%$ \\
\hline
\end{tabular}

The margin to prompt neutron criticality (1\$) of this core is $430 \pm 2 \mathrm{pcm}$. The change in reactivity by uniform coolant voiding of the active core region (no voiding outside of the core) is given in Table 8 . The total in-core coolant void worth is $8.11 \$$.

Table 8, Reference core void reactivity effect

\begin{tabular}{|l|l|l|l|l|}
\hline Condition & $\begin{array}{l}\text { Average core } \\
\text { coolant density }\end{array}$ & $\begin{array}{l}\text { Corresponding } \\
\text { uniform core coolant } \\
\text { temperature }\end{array}$ & $\mathbf{K}_{\text {eff }}$ & $\Delta \boldsymbol{\rho}(\mathbf{\$})$ \\
\hline Standard operation & $0.8506 \mathrm{~g} / \mathrm{cm}^{3}$ & $432.5^{\circ} \mathrm{C}$ & $1.00363 \pm 0.00016$ & \\
\hline $5 \%$ density drop & $0.8081 \mathrm{~g} / \mathrm{cm}^{3}$ & $615.0^{\circ} \mathrm{C}$ & $1.00453 \pm 0.00016$ & 0.21 \\
\hline $10 \%$ density drop & $0.7655 \mathrm{~g} / \mathrm{cm}^{3}$ & $791.0^{\circ} \mathrm{C}$ & $1.00649 \pm 0.00016$ & 0.67 \\
\hline $20 \%$ density drop & $0.6805 \mathrm{~g} / \mathrm{cm}^{3}$ & & $1.00967 \pm 0.00015$ & 1.41 \\
\hline $30 \%$ density drop & $0.5954 \mathrm{~g} / \mathrm{cm}^{3}$ & \multirow{2}{*}{ Boiling $\left(882^{\circ} \mathrm{C}\right)$} & $1.01367 \pm 0.00016$ & 2.34 \\
\hline $40 \%$ density drop & $0.5104 \mathrm{~g} / \mathrm{cm}^{3}$ & & $1.01665 \pm 0.00016$ & 3.03 \\
\hline
\end{tabular}




\begin{tabular}{|l|l|l|l|l|}
\hline $50 \%$ density drop & $0.4253 \mathrm{~g} / \mathrm{cm}^{3}$ & $1.02007 \pm 0.00016$ & 3.82 \\
\hline $60 \%$ density drop & $0.3403 \mathrm{~g} / \mathrm{cm}^{3}$ & $1.02380 \pm 0.00016$ & 4.69 \\
\hline $70 \%$ density drop & $0.2552 \mathrm{~g} / \mathrm{cm}^{3}$ \\
\hline $80 \%$ density drop & $0.1701 \mathrm{~g} / \mathrm{cm}^{3}$ & $1.02764 \pm 0.00015$ & 5.58 \\
\hline $90 \%$ density drop & $0.0851 \mathrm{~g} / \mathrm{cm}^{3}$ & $1.03124 \pm 0.00016$ & 6.42 \\
\hline $\begin{array}{l}\text { Complete core } \\
\text { voiding }\end{array}$ & $0 \mathrm{~g} / \mathrm{cm}^{3}$ & $1.03480 \pm 0.00016$ & 7.25 \\
\hline
\end{tabular}

The replacement of a fuel pin for an ARC-pin in each assembly causes a decrease of $0.26 \%$ in the fuel volume fraction of the core. For a given core pressure drop, coolant temperature rise and coolant velocity, replacing fuel pins by ARC pins affects the attainable power level, since less fuel and coolant channels are producing and removing the same amount of total power. To maintain the nominal power level, the pitchto-diameter ratio needs to be increased slightly for every fuel pin removed, which causes a further decrease of the fuel volume fraction. The combined effect, along with the added presence of the inner ARC-tube steel and potassium, causes a drop in the effective core multiplication factor. In addition, the pressure drop through the assemblies increases with the introduction of a lower and upper ARC reservoir. This might be compensated by an increase in the core pumping power or by an increase in P/D. As second order effect, the required duct thickness and inter-assembly gap also sees a very minor increase due to the increased pressure drop through the core. In summary, in order to maintain a critical core at nominal power when introducing ARC systems, the core geometry or fissile fraction in the fuel must be slightly altered. However, the penalty to the neutron economy by installing an ARC-system is very limited. In this example, the total drop in $\mathrm{k}_{\text {eff }}$ by installing a very comprehensive system with 6 ARC pins per assembly (out of a total 169 pins) is $2.16 \$$, which can be fully compensated in this specific system by increasing the LWR TRU fraction of the fuel by $0.13 \%$ (from $8.8 \%$ to $8.93 \%$ ). The impact of the number of fuel rods replaced by ARC tubes on core volume fractions and $\mathrm{k}_{\text {eff }}$ (without actuation of the ARC system) is summarized in Table 9. The calculations include the effect the introduction of ARC-pins has on the thermal-hydraulics of the core. The gas pressures of the systems were not studied in detail in this analysis, and the thickness of the outer ARC-tube was assumed equal to the fuel rod cladding thickness.

Table 9, Standard operation (not actuated) neutronic impact of ARC installations

\begin{tabular}{|l|l|l|l|l|l|}
\hline \# ARC & $\mathbf{K}_{\text {eff }}^{(\mathbf{a})}$ & $\begin{array}{l}\text { Fuel vol. frac. } \\
(\boldsymbol{\%})\end{array}$ & $\begin{array}{l}\text { ARC vol. } \\
\text { frac. }(\boldsymbol{\%})\end{array}$ & $\begin{array}{l}\text { Max. possible core } \\
\mathbf{6}^{\mathbf{L i}} \mathbf{~ v o l . ~ f r a c . ~}(\boldsymbol{\%})^{(\mathbf{b})}\end{array}$ & $\Delta \boldsymbol{\rho}(\mathbf{\$})$ \\
\hline 0 & 1.00363 & 44.07 & 0 & 0 & 0 \\
\hline 1 & 1.00171 & 43.74 & 0.35 & 0.24 & -0.45 \\
\hline 2 & 1.00029 & 43.40 & 0.69 & 0.48 & -0.78 \\
\hline
\end{tabular}




\begin{tabular}{|l|l|l|l|l|l|}
\hline 3 & 0.99864 & 43.07 & 1.04 & 0.73 & -1.16 \\
\hline 4 & 0.99703 & 42.73 & 1.38 & 0.96 & -1.53 \\
\hline 5 & 0.99609 & 42.54 & 1.73 & 1.21 & -1.75 \\
\hline 6 & 0.99435 & 42.18 & 2.07 & 1.44 & -2.16 \\
\hline 7 & 0.99298 & 41.85 & 2.41 & 1.68 & -2.48 \\
\hline 8 & 0.99120 & 41.51 & 2.75 & 1.92 & -2.89 \\
\hline 9 & 0.98973 & 41.18 & 3.09 & 2.15 & -3.23 \\
\hline 10 & 0.98775 & 40.84 & 3.42 & 2.38 & -3.69 \\
\hline
\end{tabular}

(a) Statistical uncertainty (SD) for all $\mathrm{K}_{\text {eff }}$ values is \pm 0.0016

(b) Max. ${ }^{6} \mathrm{Li}$ fraction is the volume of the ARC-system (the volume of a fuel rod inside of the cladding) minus the volume taken up by the inner ARC-tube. For this design, the minimum fraction of inner ARC-tube compared to the total inner rod volume is assumed to be $30 \%$, based on a minimum inner ARC-tube outer diameter of $5 \mathrm{~mm}$.

When using more than 1 ARC-pin per assembly, there is flexibility in tailoring the response time of the different pins. The requirement for a negative reactivity state at full in-core coolant voiding of the example core is a core-averaged ${ }^{6} \mathrm{Li}$ volume fraction of $0.76 \%$, nearly independent of the number of ARC-pins installed. The maximum value of ${ }^{6} \mathrm{Li}$ core volume fraction per ARC-pin is $0.24 \%$, which means that when using more than 3 ARC-pins, each individual pin does not need to introduce the maximum possible volume of ${ }^{6} \mathrm{Li}$. When using 6 ARC-pins for this core, the total possible worth of the ARC-system (with a ${ }^{6} \mathrm{Li}$ core volume fraction of $1.44 \%$ ) is nearly double what is needed to meet the S3 criteria. This leaves room for a tailoring of the response (back down to a ${ }^{6} \mathrm{Li}$ volume fraction of $0.76 \%$ ) by reducing the area available for ${ }^{6} \mathrm{Li}$ expansion. The reduction in ${ }^{6} \mathrm{Li}$ area (by increasing the radius of the inner ARC-tube) directly corresponds to an increase in the speed of actuation of the ARC-pin. A to-scale figure of a 6 ARC-pin sequential installation is shown in Figure 16. The pins provide respectively 2, 10, 16, 21, 24 and 27\% of the total negative reactivity worth of the system at full actuation.

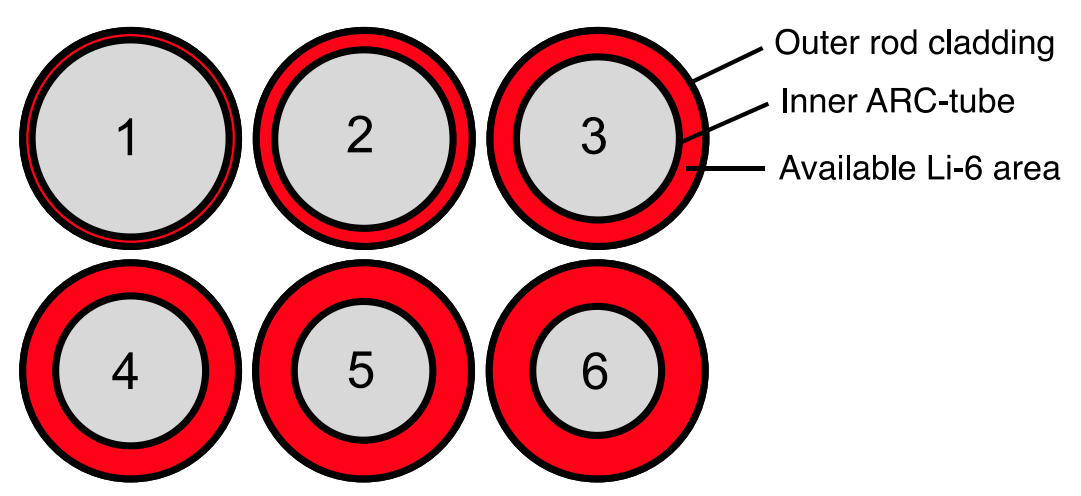

Figure 16, To-scale figure of a 6 ARC-pin sequential actuation installation 
The sequential axial response to a temperature increase in the upper ARC-reservoir can be seen in Figure 17. The width of the bars corresponds to their relative ${ }^{6} \mathrm{Li}$ volume, and the two horizontal black bars show the axial location of the active core.

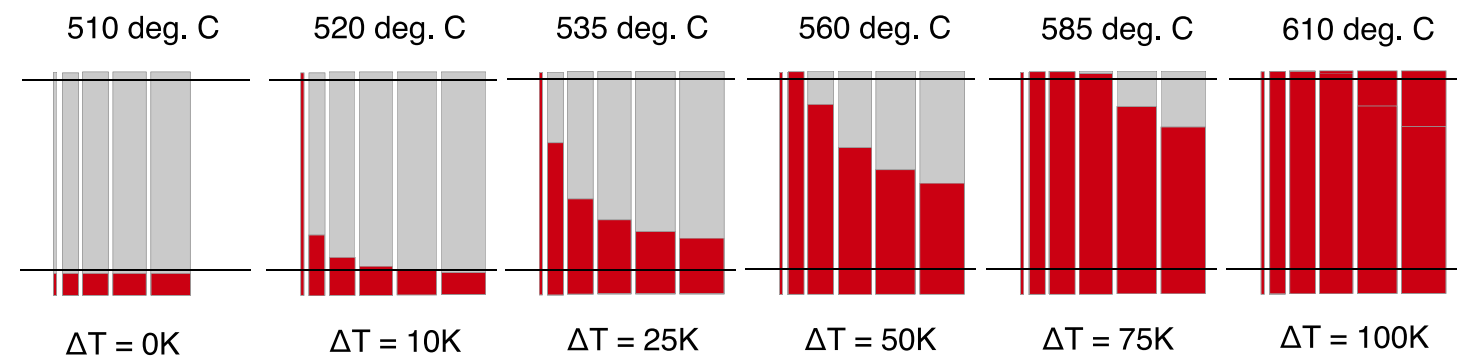

Figure 17, Axial ${ }^{6} \mathrm{Li}$-level dependence in the 6 ARC pins on ARC reservoir temperature

With a sequential-response design as seen in Figure 16 and Figure 17, the system starts to add small amounts of negative reactivity very early on in a transient scenario. If temperatures keep rising, the system continues to add more negative reactivity as the ${ }^{6} \mathrm{Li}$ in the higher-worth ARC-pins start reaching the highest worth part of the active core near the axial center. At a core-wide average ARC-reservoir temperature of $610^{\circ} \mathrm{C}$, a full $270^{\circ} \mathrm{C}$ below the coolant boiling temperature, the systems have added enough negative reactivity to provide a negative reactivity state even in the event of a complete in-core coolant voiding. As temperatures drop again, the system re-equilibrates to a state where the ${ }^{6} \mathrm{Li}$ is once again at an axial level below the core.

The possibilities for single-speed and sequential ARC-pin installations for the example core are summarized in Table 10. The number of ARC-pins in each assembly is given in the first column. All designs were adjusted to the reference criticality state $\left(\mathrm{K}_{\mathrm{eff}}=1.00363\right)$ by tailoring the TRU content in the fuel, as seen in the $2^{\text {nd }}$ column of Table 10 . The core reactivity states were calculated assuming complete in-core coolant voiding (coolant outside the core remains at reference density) and the actuation of three different ARC-system installation options. The two rightmost columns of Table 10 show the volume fraction and reactivity states assuming that the full possible reactivity worth is utilized, which precludes the use of a sequential design strategy. When the ${ }^{6} \mathrm{Li}$-level of all ARC-pins is rising at the same rate, a minimum of 4 ARC-pins per assembly is needed to meet criteria S3. The coolant density and ARC-system effect on core reactivity as a function of coolant and ARC-reservoir temperature for a 4 ARC-pin uniformly actuated system is given in Figure 18. The full actuation of the ARC-system introduces $~ 10 \$$ of negative reactivity when the ARC-reservoir temperature has risen by $150 \mathrm{deg}$. C. A full in-core coolant voiding introduces $8.1 \$$ of positive reactivity, yielding a combined core reactivity (ignoring all other reactivity feedback) of $-1.9 \$$ at the fully voided and fully ARC-actuated state, which means the system installation passes the S3 criteria. 


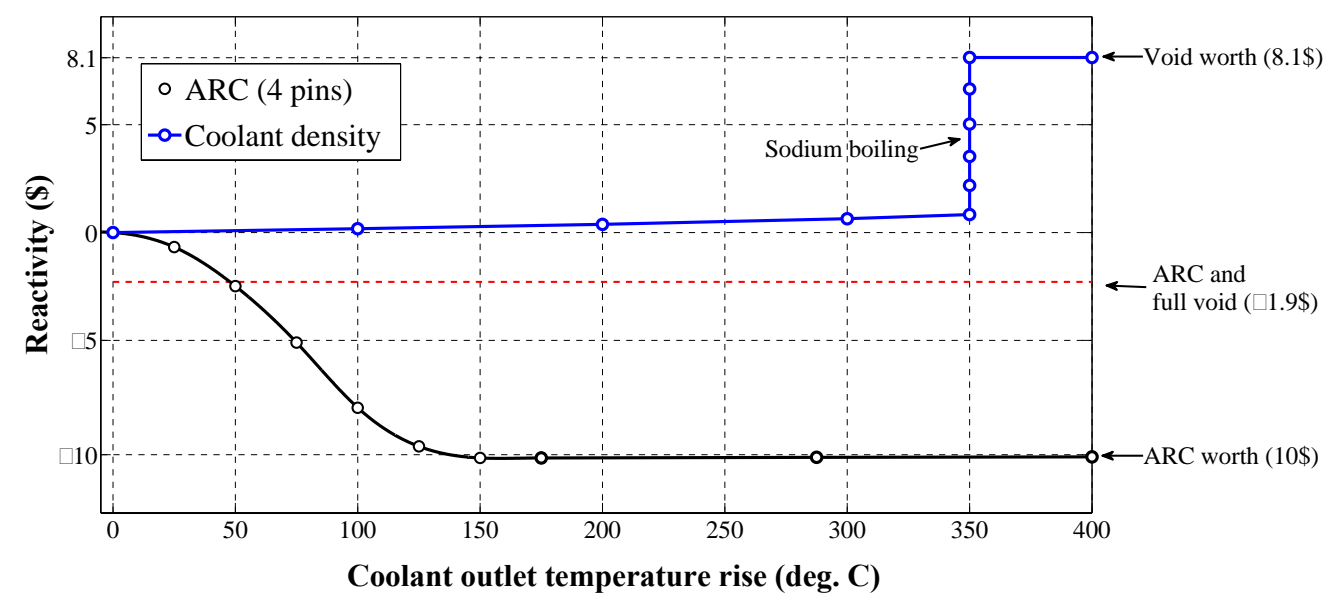

Figure 18, Coolant density and 4-pin ARC actuation effect on core reactivity as a function of the increase in the coolant (and ARC-reservoir) temperature

Using a sequential design where the total ${ }^{6} \mathrm{Li}$ volume fraction in the core is $2 / 3$ of its theoretical maximum (as seen in the mid-columns of Table 10), the S3 criteria can be met using 5 ARC-pins per assembly. If only $1 / 3$ of the total possible ${ }^{6} \mathrm{Li}$ volume fraction is used, a highly sequential time-response of the system is possible, but this would require at least 10 ARC-pins per assembly for this core design (see the bottom row of the left side of Table 10) to meet the S3 criteria.

Table 10, ARC-actuation + full in-core coolant void reactivity states

\begin{tabular}{|c|c|c|c|c|c|c|c|}
\hline \multirow[b]{2}{*}{ \# ARC } & \multirow{2}{*}{$\begin{array}{l}\text { Critical } \\
\text { (a) } \% \\
\text { TRU }\end{array}$} & \multicolumn{2}{|c|}{$\begin{array}{l}\text { 1/3 of maximum possible } \\
\text { ARC actuation }\end{array}$} & \multicolumn{2}{|c|}{$\begin{array}{l}2 / 3 \text { of maximum possible } \\
\text { ARC actuation }\end{array}$} & \multicolumn{2}{|c|}{$\begin{array}{l}\text { Full possible ARC } \\
\text { actuation }\end{array}$} \\
\hline & & $\begin{array}{l}\text { Vol. \% of } \\
{ }^{6} \mathrm{Li}\end{array}$ & $\begin{array}{l}\Delta \rho(\$) \text { at } \\
100 \% \text { void } \\
+ \text { ARC }\end{array}$ & $\begin{array}{l}\text { Vol. \% of } \\
{ }^{6} \mathrm{Li}\end{array}$ & $\begin{array}{l}\Delta \rho(\$) \text { at } \\
100 \% \text { void } \\
+ \text { ARC }\end{array}$ & $\begin{array}{l}\text { Vol. \% of } \\
{ }^{6} \mathrm{Li}\end{array}$ & $\begin{array}{l}\Delta \rho(\$) \text { at } \\
100 \% \text { void } \\
+ \text { ARC }\end{array}$ \\
\hline 1 & 8.82 & 0.08 & +7.02 & 0.16 & +6.42 & 0.24 & +5.17 \\
\hline 2 & 8.85 & 0.16 & +6.43 & 0.32 & +4.89 & 0.48 & +3.16 \\
\hline 3 & 8.87 & 0.24 & +5.19 & 0.48 & +3.17 & 0.73 & +0.29 \\
\hline 4 & 8.90 & 0.32 & +4.90 & 0.64 & +1.04 & 0.96 & -1.94 \\
\hline 5 & 8.92 & 0.40 & +4.10 & 0.80 & -0.49 & 1.21 & -4.53 \\
\hline 6 & 8.95 & 0.48 & +3.20 & 0.96 & -1.93 & 1.44 & -6.67 \\
\hline 7 & 8.97 & 0.56 & +2.39 & 1.12 & -3.73 & 1.68 & -8.99 \\
\hline 8 & 9.00 & 0.64 & +1.06 & 1.28 & -5.20 & 1.92 & -11.39 \\
\hline 9 & 9.02 & 0.72 & +0.29 & 1.44 & -6.65 & 2.15 & -13.42 \\
\hline
\end{tabular}




\begin{tabular}{|l|l|l|l|l|l|l|l|}
\hline 10 & 9.05 & 0.79 & -0.68 & 1.59 & -8.27 & 2.38 & -15.45 \\
\hline
\end{tabular}

(a) Critical is defined as critical + the uncertainty margin of the reference design: $\mathrm{K}_{\mathrm{eff}}=1.00363$

The size of the upper reservoir driving this system is determined by the temperature-span to full system actuation and particularly the expansion need for the highest worth and slowest responding pin to reach its fully actuated state. The needed expansion volume for pin \#6 in the design of Figure 16 and Figure 17 going from standard operating conditions to full actuation (with ${ }^{6} \mathrm{Li}$ covering the entire axial length of the active core) is $210 \mathrm{~cm}^{3}$. Potassium expands by approx. 0.045 vol.\% per $\mathrm{K}$ in the temperature span 510 $610^{\circ} \mathrm{C}$. To get full actuation of pin $\# 6$ at a temperature rise of the upper $\mathrm{ARC}$ reservoir of $100^{\circ} \mathrm{C}$, the required volume of ARC-reservoir potassium connected to pin \#6 is $4560 \mathrm{~cm}^{3}$, giving a total upper ARCreservoir volume of $6 \times 4560=27360 \mathrm{~cm}^{3}$. The volumetric expansion of the upper ARC-reservoir liquid between refueling $\left(200^{\circ} \mathrm{C}\right)$ and operation $\left(510^{\circ} \mathrm{C}\right)$ is $1600 \mathrm{~cm}^{3}$ and the total ${ }^{6} \mathrm{Li}$ volume per assembly is approx. $700 \mathrm{~cm}^{3}$, which determines the volume requirement of the lower ARC-reservoir. Assuming that the upper ARC reservoir occupies a (axially-averaged) fraction $\mathrm{K}_{\mathrm{x}}$ of the available volume inside of the fuel assembly, the length-addition to the fuel assembly is given by:

$$
L_{\mathrm{ARC}}=\frac{V_{e}}{A_{\mathrm{IA}} \times K_{x}}
$$

Where $\mathrm{A}_{\mathrm{IA}}$ is the area inside of the assembly duct walls and $\mathrm{V}_{\mathrm{e}}$ is expansion liquid volume

The fuel rods take up approx. 70\% of the inner assembly area in the axial level below the ARC reservoir. A matching value for $\mathrm{K}_{\mathrm{x}}$ of 0.65 is assumed, which gives a total axial height of the upper ARC-reservoir of $100 \mathrm{~cm}$. This corresponds to a length increase of the total fuel assembly structure of approx. $20 \%$. Preliminary studies show that S1 or S2 system will likely need an addition of around $20-30 \mathrm{~cm}$ to a standard fast reactor fuel assembly.

The ARC-installation example presented here gives an estimate of the maximum size and impact that an ARC-system can have. It provides a negative reactivity state in a very large fast core, at a complete in-core coolant voiding (with no coolant voiding outside of the active core), disregarding all other negative feedback, at a system temperature $270^{\circ} \mathrm{C}$ below where such a voiding could potentially occur. An ARCinstallation based on an S1 analysis strategy (see Section 7) would likely provide excellent inherent safety at only a fraction of the size of this system. In general, a S3-type of system is not recommended; it has an unnecessarily large impact on the core design and its large reactivity worth may cause severe oscillations of power and temperatures.

The ARC system does not directly fail any of the criteria of Table 1, but further studies are needed before criteria the A1 can be confidently determined not be to be a conditional fail. The temperature-delay of the system actuation is a design variable, but the time-delay has not yet been clearly quantified. The high 
conductivity metal-metal-metal heat transfer between the coolant to the ARC reservoir wall to the ARC expansion liquid is efficient and offers a very low thermal resistance.

\section{Future development plans}

Many different versions of the ARC systems have been developed. These involve different combinations of expanding and absorbing liquids, as well as the use of gas for the expansion driving force. The relative advantages and disadvantages of such systems compared to the system presented in this article will be carefully assessed. ARC system specifically designed to counter-act burnup reactivity swing in fast reactor systems is currently under study. The ARC-systems have been implemented in the SAS4A/SASSYS-1 code to enable detailed time-dependent accident scenario analysis [15]. Preliminary results from this study are highly promising, and will be a key focus of future work [16]. In addition, an electrically heated mockup system will be built (given that resources become available) to prove the general principle and to further study the time constants related to actuation. The experimental setup will also study mixing of the two liquids due to diffusion and thermal non-equilibrium during actuation, as well as the potential impact of wetting and adhesion of the expansion liquid to the ARC-tube wall. These issues may result in a reduced system performance and need to be quantified.

\section{Acknowledgements}

This work was supported by a DOE NEUP award (Project \# 09-769). 


\section{References}

[1] Hugo Van Dam, "Physics of nuclear reactor safety," Rep. Prog. Phys., vol. 11, pp. 2025-2071, 1992.

[2] E Greenspan, "Maximum Fuel Utilization in Fast Reactors Without Chemical Reprocessing," University of California Berkeley, NEUP summary project report 09-769 2012.

[3] R A Wigeland, R B Turski, and P A Pizzica, "Tradeoff of sodium void worth and burnup reactivity swing: Impacts on balanced safety position in metallic-fueled cores," in International Topical Meeting on Sodium Cooled Fast Reactor Safety, Obninsk, Russian Federation, 1994.

[4] V M Poplavsky and A M Tsiboulia, "Core design and fuel cycle of advanced fast reactor with sodium coolant," in International Conference on Fast Reactors and Related Fuel Cycles (FR09), Kyoto, Japan, 2009.

[5] A E Waltar, D R Todd, and P V Tsvetkov, Fast Spectrum Reactors. New York: Springer, 2012.

[6] E E Lewis, Fundamentals of Nuclear Reactor Physics.: Elsevier Science, 2008.

[7] J E Donoghue, "Preapplication safety evaluation report for the Power Reactor Innovative Small Module (PRISM) liquid-metal reactor. Final report," Office of Nuclear Regulation, US Nuclear Regulatory Commission, 1994.

[8] S Massara and D Verwaerde, "Physics and behaviour during a ULOF of an innovative heterogeneous annular FBR core," in Technical Meeting on Innovative Fast Reactor Designs with Enhanced Negative Reactivity Feedback Features, Vienna, Austria, 2012.

[9] N Devictor, "Pre-conceptual design study of ASTRID core," in Technical Meeting on Innovative Fast Reactor Designs with Enhanced Negative Reactivity Feedback Features, Vienna, Austria, 2012.

[10] D Schmitt, "Design of a Sodium-cooled Fast Reactor with innovative annular geometry and very low sodium void worth," in ICAPP 11, Nice, France, 2011.

[11] E Teller, M Ishikawa, and L Wood, "Completely automated nuclear reactors for long-term operation," in International Conference on Emerging Nuclear Energy Systems, Obninsk, Russia, 1996.

[12] M Kambe and M Uotani, "Design and development of fast breeder reactor passive reactivity control systems: LEM and LIM," Nuclear Technology, vol. 122, no. 2, pp. 179-185, 1998.

[13] E R Specht, "Hydraulically supported absorber balls shutdown system for inherently safe LMFBRs," in Proceedings of the International Meeting on Fast Reactor Safety and Related Physics, CITY CITY CITY, 1976.

[14] M Edelmann, G Kussmaul, and W Vath, "Improved fast reactor safety by passive shut-down," Progress in Nuclear Energy, vol. 29, pp. 379-386, 1995.

[15] T H Fanning, "The SAS4A/SASSYS-1 Safety Analysis Code System, ANL/NE-12/4," Nuclear Engineering Division, Argonne National Laboratory, Argonne, IL, Manual 2012.

[16] E Suvdantsetseg, "To be published," Royal Institute of Technology, Stockholm, Sweden, 2013.

[17] F Hargreaves, G T. J Mayo, and A G Thomas, "A study of the long-term compatibility of thermionic converter materials with caesium," Journal of Nuclear Materials, vol. 18, no. 2, pp. 212-218, 1996.

[18] C Dasarathy, "Some Observations on the Liquid Immiscible Nature of the Iron-Indium and Aluminium-Indium Systems," Z. anorg. allg. Chem., vol. 403, pp. 173-175, 1974.

[19] K Natesan, C B Reed, and F Mattas R, "Assessment of alkali metal coolants for the ITER blanket," Fusion Engineering and Design, vol. 27, pp. 457-466, 1995.

[20] T R Pinchback and D A Knecht, "The Development of Process and Storage Materials Suitable for Krypton-85 Waste Management," in Scientific Basis for Nuclear Waste Management, G. J. McCarthy, Ed.: Springer US, 1979, pp. 479-485.

[21] C W Bale, "The Cs-Li (Cesium-Lithium) system," Bulletin of Alloy Phase Diagrams, vol. 10, no. 3, pp. 232-233, 1989.

[22] J Songster and D Pelton, "The In-Li (Indium-Lithium) System," Journal of Phase Equilibria, vol. 12, no. 1, pp. 37-41, 1991.

[23] F J Smith, "The limits of miscibility in the lithium-potassium system," Journal of the Less Common Metals, vol. 35, no. 1, pp. 147-151, 1974. 
[24] C W Bale, "The Li-Rb (Lithium-Rubidium) system," Bulletin of Alloy Phase Diagrams, vol. 10, no. 3, pp. 268-269, 1989.

[25] W E Brooks, "Cesium (Cs)," in USGS Metal Prices in the United States Through 2010., 2013.

[26] A C Tolcin, "Indium (In)," in USGS Metal Prices in the United States Through 2010., 2013.

[27] T L Roberts, "Global Potassium Reserves and Potassium Fertilizer Use," in INPI 2008 Join Annual Meeting, 2008.

[28] W E Brooks, "Rubidium (Rb)," in USGS Metal Prices in the United States Through 2010., 2013.

[29] A C Tolcin, "Mineral Commodity Profiles - Indium," in U.S. Geological Survery, Mineral Commodity Summaries., 2012.

[30] W C Butterman, W E Brooks, and R G Reese, "Mineral Commodity Proflies - Cesium," in USGS Open-File Report 2004-1432., 2005.

[31] A C Tolcin, "Mineral Commodity Profiles - Indium," in U.S. Geological Survey, Mineral Commodity Summaries., 2007.

[32] S A Basin and Solov'ev, "Investigation of the density of liquid lead, cesium, and gallium by the gamma-method," Journal of Applied Mechanics and Technical Physics, vol. 8, no. 6, pp. 57-59, 1967.

[33] M J Assael et al., "Reference Data for the Density and Viscosity of Liquid Cadmium, Cobalt, Gallium, Indium, Mercury, Silicon, Thallium, and Zinc," Journal of Physical and Chemical Reference Data, vol. 41, no. 3, 2012.

[34] R W Ohse, Handbook of thermodynamic and transport properties of alkali metals, R W Ohse, Ed. Oxford, UK: Blackwell Scientific, 1985.

[35] Wolfram Research. (2013, Sep.) Wolfram Alpha. [Online]. www.wolframalpha.com/input/?i=density+rubidium

[36] S Qvist, "The ADOPT fast reactor core design code," University of California Berkeley, Berkeley, CA, US, Technical Report 2012.

[37] J Leppänen, "Serpent Monte Carlo Physics Code," in AER Symposium on VVER Reactor Physics and Reactor Safety, Espoo, Finland, 2010.

[38] M B Chadwick, "ENDF/B-VII. 0: Next generation evaluated nuclear data library for nuclear science and technology," Nuclear Data Sheets, vol. 107, no. 12, pp. 2931-3060, 2006.

[39] B Merk, E Fridman, and F P Weiss, "On the use of a moderation layer to improve the safety behavior in sodium cooled fast reactors," Annals of Nuclear Energy, vol. 38, no. 5, pp. 921-929, 2011.

[40] M J Driscoll, P Hejzlar, and G Apostolakis, "Optimized, Competitive Supercritical-CO2 Cycle GFR for Gen IV Service," MIT, MIT-GFR-045 2008.

[41] S Qvist, "USPTO provisional patent BK-2013-005-1 (Nuclear Fuel Assembly Reactivity Control System)," University of California Berkeley, Berkeley, CA, US, 2012.

[42] S Qvist, "Reactivity feedbacks of breed-and-burn cores," in American Nuclear Society Annual Meeting, Hollywood, FL, US, 2011.

[43] S Qvist and E Greenspan, "Inherent Safety of Breed and Burn Reactors," in International Congress on Advances in Nuclear Power Plants, Chicago, IL, US, 2012.

[44] R G Smith, F Hargreaves, G T. J Mayo, and A G Thomas, "A study of the compatibility of thermionic converter materials with caesium," Journal of Nuclear Materials, vol. 10, no. 3, pp. 191-200, 1963.

[45] Neil E Todreas and Mujid S Kazimi, Thermal Hydraulic Fundamentals 1 \& 2, Second Edition. Cambridge, MA, US: Taylor \& Francis, 2011, vol. 1 \& 2.

[46] W P Barthold, "Constrained Nuclear Design," in Advanced Reactors; Physics, Design and Economics , Atlanta, Georgia, 1974.

[47] X-5 Monte Carlo Team, "MCNP - A General N-Particle Transport Code, Version 5," Los Alamos National Laboratory, Los Alamos, NM, US, 2005.

[48] J Leppänen, "Serpent Progress Report 2011," VTT, Espoo, 2012.

[49] S Qvist, "Assemby Design and Optimization (ADOPT) Code," University of California Berkeley, Berkeley, CA, US, Technical Report 2012. 
[50] L S Tong and J Weisman, Thermal Analysis of Pressurized Water Reactors. Lagrange Park, Illinois, USA: American Nuclear Society, 1991.

[51] ASME, "Boiler \& Pressure Vessel Code, Section VIII, Division 1, Subsection A, Article UG-27, ," ASME, New York, 2005.

[52] V Sobolev and E Malambu, "Design of a fuel element for a lead-cooled fast reactor," Journal of Nuclear Materials, vol. 385, pp. 392-399, 2009.

[53] K Mikityuk, "Heat transfer to liquid metal: Review of data and correlations for tube bundles ," Nuclear Engineering and Design, vol. 239, pp. 680-687, 2009.

[54] S Cheng and N Todreas, "Hydrodynamic models and correlations for bare and wire-wrapped hexagonal rod bundles - Bundle friction factors, subchannel friction factors and mixing parameters," Nuclear Engineering and Design, vol. 92, pp. 227-251, 1986.

[55] E Bubelis and M Schikorr, "Review and proposal for best fit of wire-wrapped fuel bundle friction factor and pressure drop predictions using various existing correlations ," Nuclear Engineering and Design, vol. 238, pp. 3299-3320, 2008.

[56] C D Flowers, "STRUCTURAL ANALYSIS OF A HEXAGONAL TUBE OR RING UNDER INTERNAL PRESSURE," Pacific Northwest National Laboratory (PNNL), Technical Report 1966.

[57] ANL / CEA / JNC, "Small Modular Fast Reactor Design Description," Argonne National Lab, Commesariat a l'Energie Atomique / Japan Nuclear Cycle Development Institute, Chicago, 2005.

[58] S K Cheng, R Petroski, and N E Todreas, "Numerical implementation of the Cheng and Todreas correlation for wire wrapped bundle friction factors-desirable improvements in the transition flow region," Nuclear Engineering and Design, vol. 263, pp. 406-410, 2013.

[59] S. Pramuditya, "Cheng-Todreas Correlations Calculator," Tokyo Institute of Technology, Software 2010.

[60] R Thiele, "Flow pattern analysis in ELECTRA under natural circulation condition of liquid lead," in GENIUS-Project Meeting 2013, Gimo, Sweden, 2013. 


\section{Footnotes}

1. Ref. [11] proposes the need of 1000 thermo-stat modules per GWe of core output.

2. Reactivity effects such as cladding radial thermal expansion and the radial expansion of fuel at low burnup are positive, but of such small magnitude that they are of low importance to reactor safety.

3. The S2 strategy (and with a very large likelihood S1) requirements would be met with 3 or less pins per assembly. 